\title{
Tribological Properties of Cylinder Block/ Valve Plate Interface of Axial Piston Pump on the Tribometer
}

\author{
Jiahai Huang ${ }^{*}{ }^{\mathbb{D}}$, Zhenhua Dou, Zhenglei Wang ${ }^{*}$, Long Quan and Linkai Niu
}

\begin{abstract}
The tribological properties of cylinder block/valve plate is an important consideration in the design of axial piston pump. The effect of materials and heat treatment on friction and wear properties has been studied in depth. Engineering experiences show that the speed and load also affect the tribological properties, but these have not been systematically analyzed. The purpose of this paper is to evaluate the tribological properties of the commonly used materials (CuPb15Sn5 and 38CrMoAl/42CrMo) for cylinder block/valve plate with different heat treatment and contact pressure at different speed. During the test, tribometer is used to simulate the contact pattern between the valve plate/cylinder block in axial piston pump, the friction coefficient, wear rate and surface topography are analyzed to evaluate the tribological properties of different types of friction samples at different speed. Results indicate that: (1) contact surface of the samples at $1800 \mathrm{r} / \mathrm{min}$ is more prone to adhesive wear than those at $500 \mathrm{r} / \mathrm{min}$; (2) in the terms of wear resistance, quench-tempered and nitrided 38CrMoAl (38CrMoAl QTN for short) is better than quench-tempered and nitrided $42 \mathrm{CrMo}$, although they are all commonly used materials in the axial piston pump; (3) $2.5 \mathrm{MPa}$ is the critical contact pressure of the interface between valve plate made of 38CrMoAI QTN and cylinder block made of CuPb15Sn5 on the tribometer, which implies the pressure bearing area at the bottom of the cylinder block should be carefully designed; (4) the valve plate/cylinder block made of 38CrMoAI QTN/CuPb15Sn5 exhibits good tribological properties in a real axial piston pump. This research is useful for the failure analysis and structural optimization design of the valve plates/cylinder block.
\end{abstract}

Keywords: Axial piston pump, Valve plate/cylinder block, Tribological properties, Heat treatment, Tribometer

\section{Introduction}

Axial piston pump is widely used in industrial applications such as aerospace, agriculture and heavy machinery because of its excellent operating performance [1, 2]. In axial piston pumps, the valve plate/cylinder block interface is one of the key tribological pairs, and plays an important impact on the pump performance [3, 4].

Researchers have conducted extensive researches on the friction and wear properties of the valve plate/cylinder block [5-7]. Zhao et al. [8] studied the tribological

\footnotetext{
*Correspondence: huangjiahai@tyut.edu.cn; 312734826@qq.com College of Mechanical and Vehicle Engineering, Taiyuan University of Technology, Taiyuan 030024, China
}

properties of the valve plate/cylinder block made of PEEK/38CrMoAlA under the condition of $3 \#$ aviation kerosene lubrication. Zhu et al. [9] investigated the influence of surface morphology on its tribological properties under low-speed conditions, which indicated that the smooth surface could significantly improve its tribological properties. Some researchers investigated the effects of coatings on its friction and wear properties under low-speed conditions, in which duplex TiN [10], PVD TiN [11], CrSiN [12], and $\mathrm{Cr}-\mathrm{X}-\mathrm{N}(\mathrm{X}=\mathrm{Zr}, \mathrm{Si})$ [13] were coated onto the cylinder block surface, and results indicated that both the friction coefficient and wear rate could be significantly reduced. Chen et al. [14] applied low temperature plasma nitriding (LPN) into 38CrMoAl 
hydraulic plunger and got compound layer on its surface, the results showed that the heat treatment could effectively improve its tribological properties. Schuhler et al. [15] found that the wear resistance of stainless steel was improved after nitriding.

Li et al. $[16,17]$ investigated the performance of the friction pairs with textured valve plate in the range of 150-750 r/min, and pointed out that both the friction coefficient and wear rate were reduced. Deng et al. [18-20] pointed out that the textured valve plate could increase oil-film stiffness and reduce the leakage. Wu et al. [21, 22] studied the friction and wear properties of bionic non-smooth surfaces on the valve plate/cylinder block (glass fiber-epoxy resin), and found that this configuration lowered friction coefficient and wear rate.

In short, the above researches mainly focused on the following two aspects: (1) improving the friction performance by covering wear-resistant materials or deploying texture on the surfaces between the valve plate and the cylinder block; (2) exploring the effect of surface morphology and heat treatment on its friction and wear properties. It should be noted that most of the researches related to the valve plate/cylinder block were carried out on a tribometer under low-speed conditions $(\leq 1000 \mathrm{r} /$ $\min$ ).

To reduce friction and wear, the valve plate/cylinder block is designed to create a full film to balance most external loads and prevent contact between the metallic surfaces of tribological pairs. But under some extreme conditions, such as overload or excessive oil temperature, the fluid film lubrication might break down, so that the interface transitions to boundary lubrication or mixed lubrication. In this case, the surfaces of the material are so close that contact might occur between the asperities, which could result in severe wear, metal adhesion and eventually failure of the tribological pairs. Research results have shown that both operating speed and contact pressure play an important impact on the performance of the rotating friction pair [23-25]. Undoubtedly, in the case of boundary lubrication or mixed lubrication, the operating speed and contact pressure must have an important effect on its friction and wear properties as well. However, these problems have not been systematically discussed yet.

The aim of this work is to investigate how the operating speed, contact pressure and heat treatment affect the tribological properties of valve plate/cylinder block samples made of $38 \mathrm{CrMoAl} / 42 \mathrm{CrMo}$ and $\mathrm{CuPb} 15 \mathrm{Sn} 5$ under the conditions of boundary lubrication and/or mixed lubrication; understand the dominant wear mechanisms and the possible failure mode. During the test, tribometer is used to simulate the contact pattern between the valve plate/cylinder block in axial piston pump. Then friction coefficient, wear rate and surface topography are used to evaluate the tribological properties of valve plate/cylinder block at a speed of $1800 \mathrm{r} / \mathrm{min}$ because pumps are usually driven by 4-pole electric motors and operate at a speed of approximately $1500 \mathrm{r} / \mathrm{min}$ in most industrial applications. These findings is useful for the failure analysis and structural optimization design of the valve plates/ cylinder block.

\section{Test Details}

\subsection{Contact Between Valve Plate and Cylinder Block}

Sketch of the valve plate/cylinder block in an axial piston pump is shown in Figure 1. As shown, the valve plate is fixed in the rear cover of the pump (not shown), cylinder block is pressed against the valve plate to create a sealing surface by combination of spring and the force generated by high-pressure oil acting on the bottom of the cylinder block. To reduce power loss at the cylinder block and valve plate interface, the contact area is limited to two rings known as "balance lands". To reduce wear, it is typical to have the valve plate or the cylinder block coated with the soft material, such as brass, red copper or bronze, while the opposing surface is usually

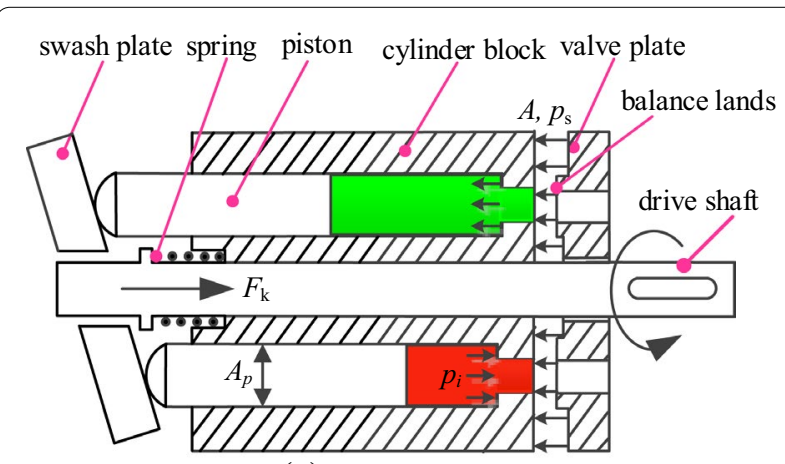

(a) sectional view

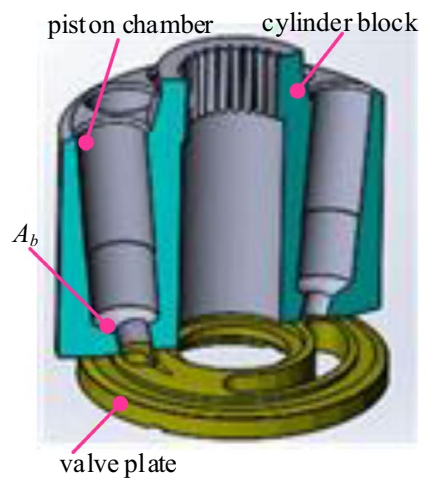

(b) valve plate / cylinder block

Figure 1 Sketch of the valve plate/cylinder block within the axial piston pump 
characterized by the steel or ductile iron surface, for example $38 \mathrm{CrMoAl}$ or $42 \mathrm{CrMo}$.

With the help of drive shaft, the cylinder block rotates on the surface of the valve plate; while it rotates, the pistons nested in the cylinder block reciprocate in the piston chambers, then the oil is sucked in or discharged out of the piston chambers. The friction torque, $M_{f}$ between the valve plate and cylinder block can be expressed as follows:

$$
\begin{aligned}
& F_{f}=\mu \cdot\left(F_{p}+F_{k}-F_{o}\right), \\
& F_{p}=\sum_{i=1}^{n} A_{b} \cdot p_{i}, \\
& F_{o}=A \cdot p_{s}, \\
& M_{f}=r \cdot F_{f},
\end{aligned}
$$

where $F_{f}$ is friction force, $\mu$ is friction coefficient; $r$ is torque arm of the force with regard to drive shaft; $F_{p}$ is the pressure-clamping force caused by instantaneous pressure in each piston/cylinder chamber, $p_{i} ; A_{b}$ is the effective pressurized area in a single piston bore; $n$ is the number of pistons; $F_{k}$ is spring force; $F_{o}$ is bearing force;

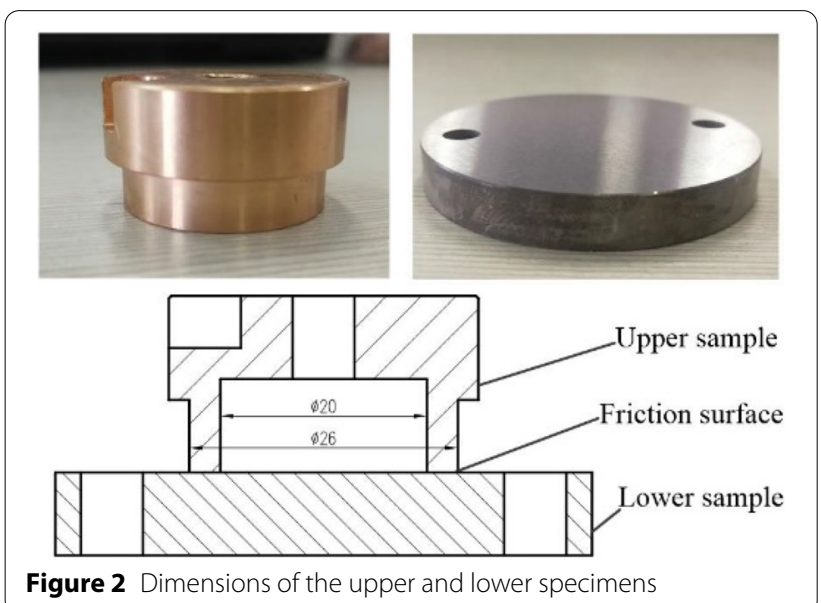

$p_{s}$ is oil film pressure between friction pairs; $A$ is effective area of oil film.

\subsection{Test Specimens}

The dimensions of the specimens are shown in Figure 2. As shown, the upper sample used to simulate the cylinder block is made of CuPb15Sn5; the outer diameter of friction surface is $26 \mathrm{~mm}$, the inner diameter of friction surface is $20 \mathrm{~mm}$. The base material of the lower sample simulating the valve plate is $38 \mathrm{CrMoAl}$ or $42 \mathrm{CrMo}$. Material compositions of the samples are shown in Table 1. $38 \mathrm{CrMoAl}$ is a kind of nitriding steel, it has excellent heat resistance and corrosion resistance, 42CrMo has high toughness and hardenability. CuPb15Sn 5 is one of the materials commonly used in the application of the axial piston pump cylinder block, the lead particles are distributed in the copper substrate; since the lead element acts as a solid lubricant during friction process, CuPb15Sn5 has a low friction coefficient.

For comparison, there are 6 sets of specimens, namely, 2 experiment groups and 4 control groups. The upper samples of these 6 groups are all made of $\mathrm{CuPb} 15 \mathrm{Sn} 5$. As listed in Table 2, NHT means 'no heat treatment', NT represents 'nitriding treatment', and QTN is 'quenching, tempering and nitriding treatment'. The upper/lower sample of 'Experiment 1' is made of $\mathrm{CuPb} 15 \mathrm{Sn} 5 / 38 \mathrm{CrMoAl}$ QTN. The upper/lower sample of 'Experiment2' is made of CuPb15Sn5/42CrMo QTN.

Physical phases of the lower samples were examined by XRD (X-Ray Diffraction). As shown in Figure 3(a), there is only $\alpha-\mathrm{Fe}$ in the samples of $38 \mathrm{CrMoAl} \mathrm{NHT}$

\begin{tabular}{|c|c|c|c|c|c|c|c|c|c|}
\hline Composition & $\mathrm{C}$ & Si & $\mathrm{Mn}$ & Al & $P$ & $\mathrm{Cr}$ & $S$ & $\mathrm{Ni}$ & Mo \\
\hline 38CrMoAl & $0.35-0.42$ & $0.20-0.45$ & $0.30-0.60$ & $0.70-1.10$ & $\leq 0.035$ & $1.35-1.65$ & $\leq 0.035$ & $\leq 0.030$ & $0.15-0.25$ \\
\hline $42 \mathrm{CrMo}$ & $0.38-0.45$ & $0.17-0.37$ & $0.50-0.80$ & - & $\leq 0.035$ & $0.90-1.20$ & $\leq 0.035$ & $\leq 0.030$ & $0.15-0.25$ \\
\hline Composition & $\mathrm{Cu}$ & Sn & $\mathrm{Pb}$ & $\mathrm{Ni}$ & $\mathrm{Zn}$ & Other & & & \\
\hline CuPb15Sn5 & Margin & $4.0-6.0$ & $14.0-16.8$ & $1.0-2.0$ & $<0.05$ & $<1.0$ & & & \\
\hline Result & Margin & 4.6 & 15.36 & 1.37 & $<0.03$ & $<1.0$ & & & \\
\hline
\end{tabular}

Table 2 Experiment group arrangement

\begin{tabular}{lll}
\hline Groups & Upper samples & Lower samples \\
\hline Control group 1 & CuPb15Sn5 & 38CrMoAl NHT \\
Control group 2 & CuPb15Sn5 & 38CrMoAl NT \\
Experiment 1 & CuPb15Sn5 & 38CrMoAl QTN \\
Control group 3 & CuPb15Sn5 & 42CrMo NHT \\
Control group 4 & CuPb15Sn5 & 42CrMo NT \\
Experiment 2 & CuPb15Sn5 & 42CrMo QTN \\
\hline
\end{tabular}

Table 1 Material composition of the specimens (\%) 


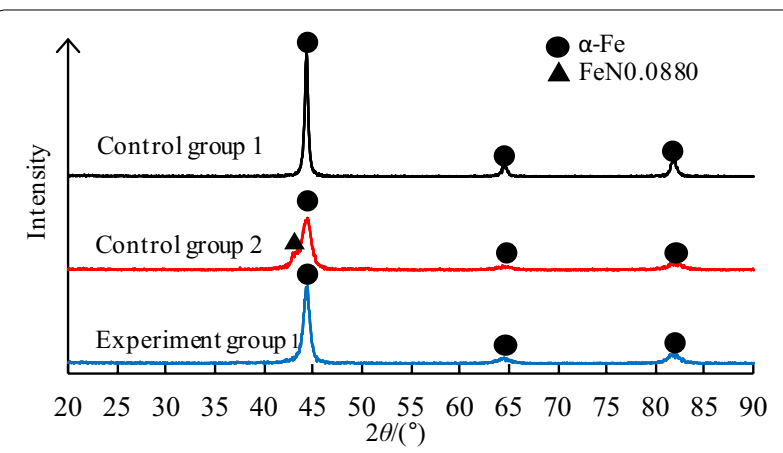

(a) $38 \mathrm{CrMoAl}$

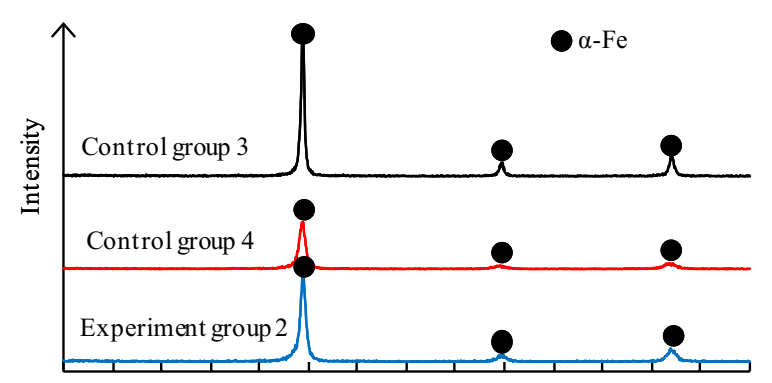

$\begin{array}{lllllllllllllll}20 & 25 & 30 & 35 & 40 & 45 & 50 & 55 & 60 & 65 & 70 & 75 & 80 & 85 & 90\end{array}$

(b) $42 \mathrm{CrMo}$

Figure 3 XRD diffraction pattern of the lower samples

and $38 \mathrm{CrMoAl} \mathrm{QTN}$; there is a small amount of nitride in the samples of $38 \mathrm{CrMoAl}$ NT besides $\alpha$-Fe, because the nitride on the surfaces of the samples were not completely removed in the grinding stage. And there is only $\alpha$-Fe in the samples of $42 \mathrm{CrMo} \mathrm{NT}, 42 \mathrm{CrMo} \mathrm{NHT}$ and 42 CrMo QTN, as shown in Figure 3(b). Therefore, it can be concluded that the physical phase of these lower samples is similar.

The lower samples listed in Table 2 were cut perpendicularly. Their cross sections were polished and etched with $4 \%$ nitric acid alcohol solution. Their metallographic structure were observed by means of a metallographic microscope. Since both $38 \mathrm{CrMoAl}$ and $42 \mathrm{CrMo}$ are hypoeutectoid steel, it can be found that the microstructures of these two samples with NHT (Figure 4(a), (d)) are ferrite and pearlite. The microstructures of the samples with NT (Figure 4(b), (e)) are still ferrite and pearlite, and those with QNT are tempered sorbate (Figure 4(c), (f)).

Surface hardness of the samples was measured by Vickers hardness tester under $10 \mathrm{~kg}$ load condition. Mean values were obtained by 5 repeated measurements. Hardness of each group is shown in Table 3. As shown, the surface hardness of $\mathrm{CuPb} 15 \mathrm{Sn} 5$ is $104 \mathrm{HV}$; the surface hardness of $38 \mathrm{CrMoAl} \mathrm{NHT}$ is almost the same as that of 42CrMo NHT, namely, $216 \mathrm{HV}$ and $218 \mathrm{HV}$. It seems that both nitriding process and quenching, tempering and nitriding treatment can significantly improve the surface hardness. It indicates the surface hardness of $38 \mathrm{CrMoAl}$ NT and $38 \mathrm{CrMoAl}$ QTN is higher than that of $42 \mathrm{CrMo}$ NT and 42CrMo QTN. The original morphology of the upper and lower samples is shown in Figure 5, their surface roughness are $0.2 \mu \mathrm{m}$ and $0.4 \mu \mathrm{m}$, respectively.

\subsection{Test Equipment and Procedure}

Wear tests were performed by means of the ring-ondisk tribometer, MMU-10H, shown in Figures 6 and 7. As shown, the upper sample simulating the cylinder block was mounted on the tester's shaft driven by a servo motor, its speed range is $0-2000 \mathrm{r} / \mathrm{min}$; the lower sample simulating the valve plate was fixed on the bottom of the stationary oil box that was connected to the loading hydraulic cylinder through a ball join. The hydraulic cylinder in the rig generates force and applies the force to the tested sample. During the test, the load can be adjusted by changing the force of the hydraulic cylinder. L-HM46 is a mineral oil, and widely used in the hydraulic control system to transmit power. To make the test conditions consistent with the valve plate/cylinder block in a real axial piston pump, L-HM 46 hydraulic oil is injected into the cavity between the upper and lower samples by means of gear pump, it acts as a coolant and lubricant; after that, it returns to the oil tank. The main properties of L-HM46 are listed in Table 4.

During the experiment, the thermocouple fixed at the bottom of the oil box detects the temperature in real time. The torque sensor and load sensor measure the friction torque and the loading force, respectively. The computer installed in the test rig is used to regulate the force generated by hydraulic cylinder and the rotation speed of the upper sample; in addition, it collects the friction coefficient and temperature. The sampling interval is $0.1 \mathrm{~s}$.

As mentioned above, the hydraulic cylinder generates a normal force $F_{N}$ to the interface between the upper and lower samples. The maximum output force is $10 \mathrm{kN}$, and its accuracy is $\pm 1 \%$ FS. The friction torque $T$ is acquired by a sensor. Therefore, the friction coefficient $\mu$ can be calculated by

$$
\mu=\frac{T}{F_{N} \cdot R},
$$

where $R$ is the torque arm of $F_{N}$ with regard to the shaft.

The contact pressure, $P_{\text {Load }}$ is calculated by

$$
p_{\text {Load }}=\frac{F_{N}}{A},
$$

where $A$ is the maximum contact area. 


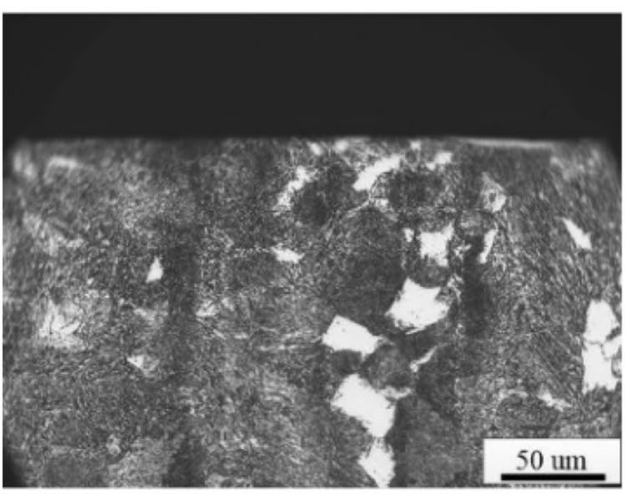

(a) Control group 1

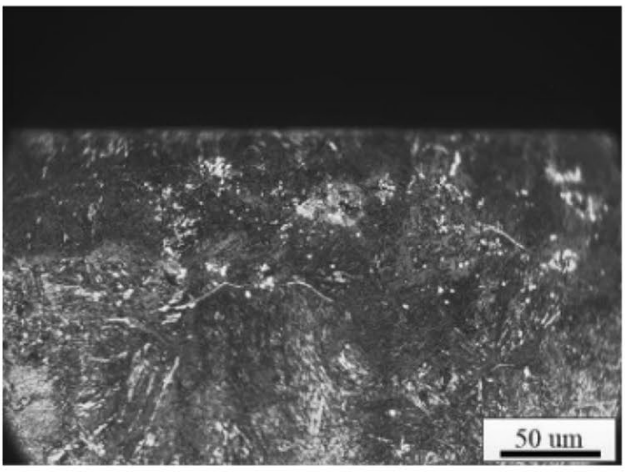

(c) Experiment 1

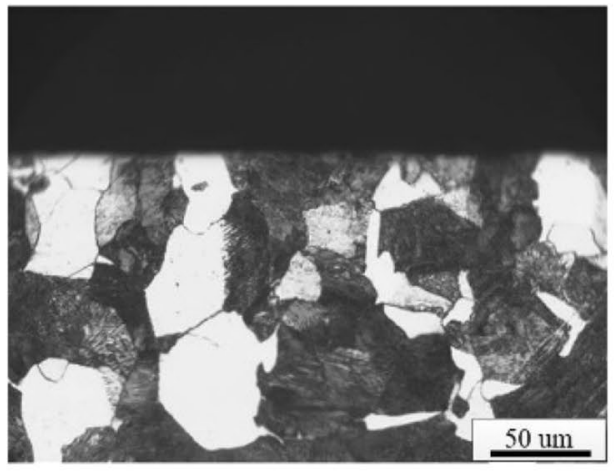

(e) Control group 4

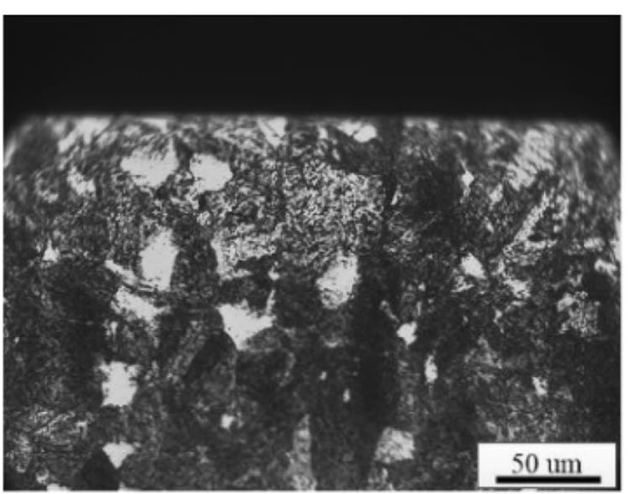

(b) Control group 2

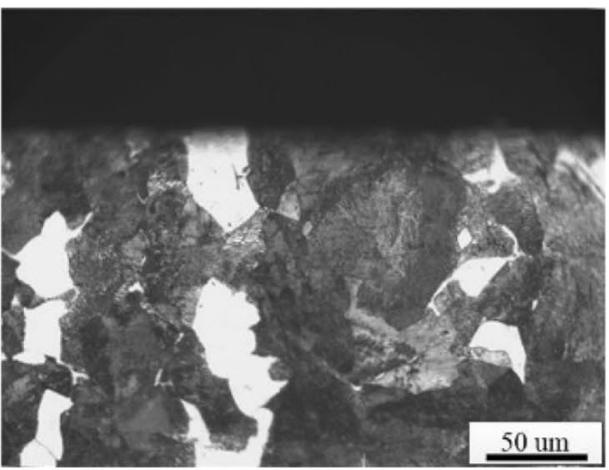

(d) Control group 3

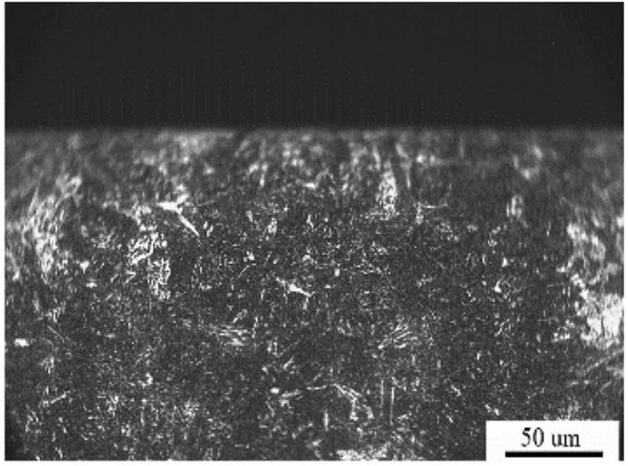

(f) Experiment 2

Figure 4 Metallographic of the lower sample section

Table 3 Surface hardness of the lower sample (HV)

\begin{tabular}{llll}
\hline Material & NHT & NT & QTN \\
\hline 38CrMoAl & 216 & 724 & 772 \\
42 CrMo & 218 & 572 & 642 \\
CuPb15Sn5 & 104 & - & - \\
\hline
\end{tabular}

In most industrial applications, axial piston pumps are typically driven by 4-pole motors and operate at speed of approximately $1500 \mathrm{r} / \mathrm{min}$ although their rated speed are usually higher than that. In addition, the maximum operating speed of the tribometer is $2000 \mathrm{r} / \mathrm{min}$. Therefore, the maximum speed during the test is determined to be $1800 \mathrm{r} / \mathrm{min}$, which is slightly higher than $1500 \mathrm{r} / \mathrm{min}$. 


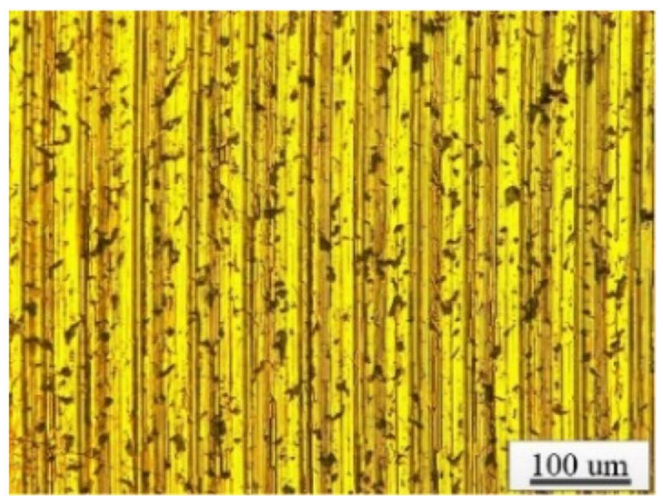

(a) Upper sample

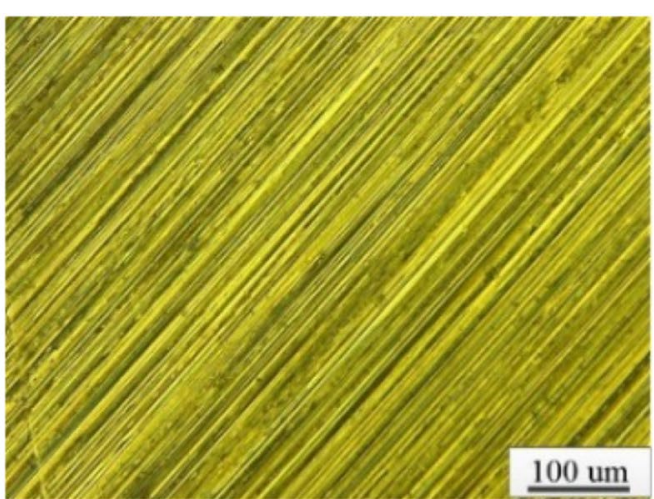

(b) Lower sample

Figure 5 Surface topography of the upper and lower samples (unworn condition)

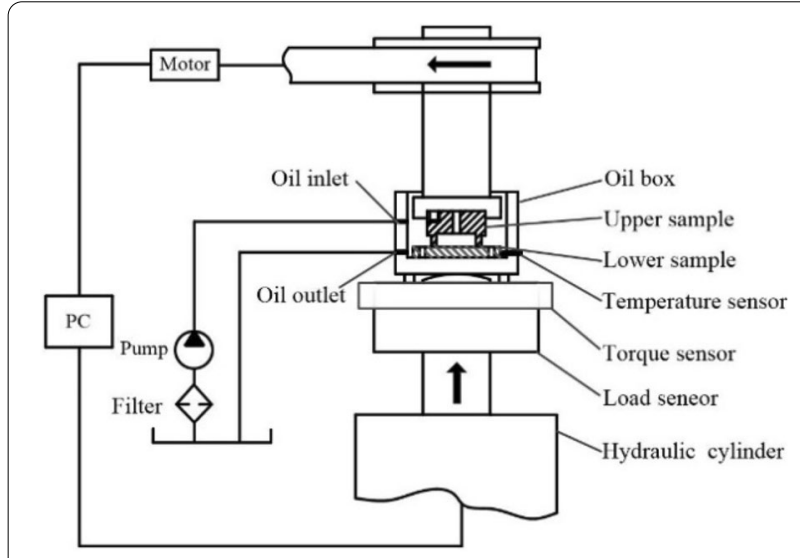

Figure 6 Sketch of the ring-on-disk tribometer
In each cycle, the upper sample rotated 27430 times, namely, the sliding distance was $2000 \mathrm{~m}$, which was equal to the number of revolutions by the radial center perimeter of friction ring. Lubricant flow rate was $1.5 \mathrm{~mL} / \mathrm{s}$. System temperature was adjusted to $23 \pm 1{ }^{\circ} \mathrm{C}$ before test. Each test was repeated 3 times. All samples were ultrasonically cleaned with acetone solution for ten minutes before and after the test, then washed with alcohol and dried for weighing. Accuracy of the analytical balance is $1 \mathrm{mg}$. Each sample was weighed five times and then the average was calculated. After that, surface topography of the sample was observed using VHX-5000 super deep scene 3D microscope.

\section{Results}

\subsection{Effect of Speed on the Tribological Characteristics}

In this section, the test object is the 'Experiment 1' in Table 2. The contact pressure was adjusted to 3

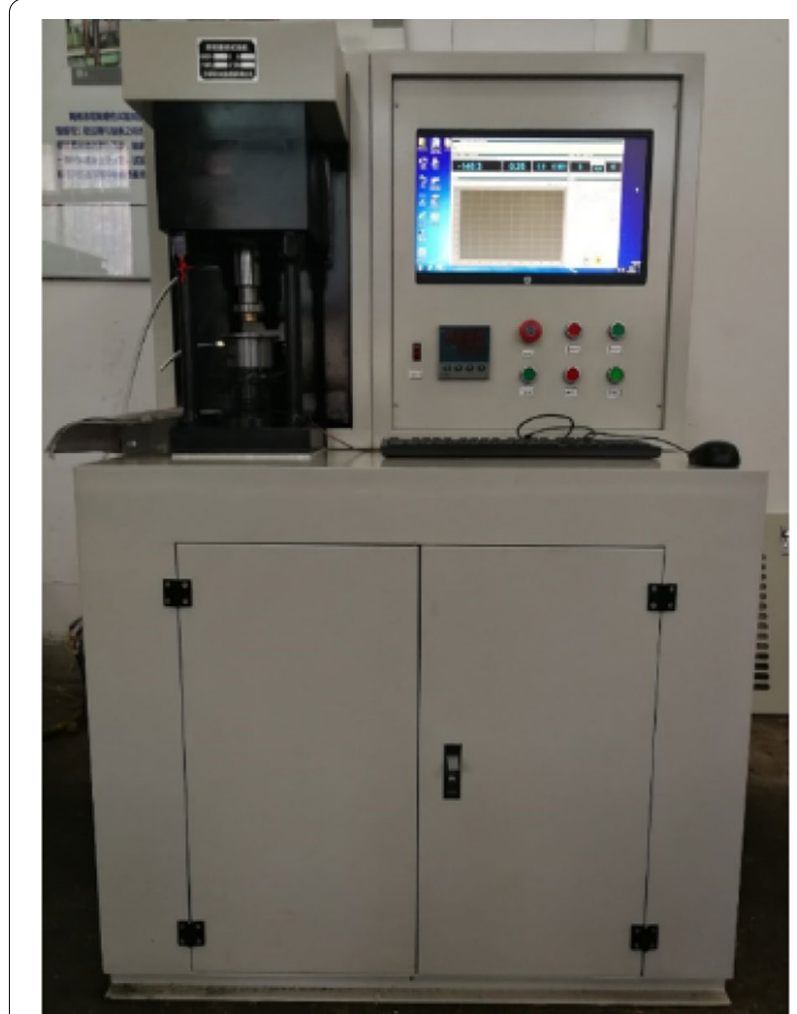

Figure 7 Photograph of the ring-on-disk tribometer

$\mathrm{MPa}$, and the speed was $500 \mathrm{r} / \mathrm{min}$ and $1800 \mathrm{r} / \mathrm{min}$, respectively. Due to the difference in surface hardness between the upper and lower samples, wear mainly occurs on the upper samples made of $\mathrm{CuPb} 15 \mathrm{Sn} 5$. Therefore, only the wear rate of the upper samples is calculated as the measured mass loss divided by the sliding distance, the unit is $\mathrm{mg} / \mathrm{m}$. 
Table 4 Properties of L-HM46

\begin{tabular}{ll}
\hline Properties & Value \\
\hline Density $\left(\mathrm{kg} / \mathrm{m}^{3}\right)$ & 870 \\
Average bulk modulus $(\mathrm{Pa})$ & $2 \times 10^{9}$ \\
Max. operating temperature range $\left({ }^{\circ} \mathrm{C}\right)$ & $-20 \sim 90$ \\
Flash point $\left({ }^{\circ} \mathrm{C}\right)$ & 234 \\
Flow point $\left({ }^{\circ} \mathrm{C}\right)$ & -12 \\
Erosion effect & Good \\
Wear protection capability & Very good \\
\hline
\end{tabular}

The friction coefficients at $500 \mathrm{r} / \mathrm{min}$ and $1800 \mathrm{r} / \mathrm{min}$ are respectively shown in Figure 8 . At the speed of 500 $\mathrm{r} / \mathrm{min}$, it gradually increases, then reaches a stable wear stage; the stable value is 0.105 . In regard to $1800 \mathrm{r} / \mathrm{min}$, the friction coefficient fluctuates between 0.045 and 0.08 , and there was a huge noise during the test. After the test, it was found that a large amount of loose copper particles or wear debris were accumulated between the friction pairs. All of these phenomena indicate that the friction at $1800 \mathrm{r} / \mathrm{min}$ is unstable. Their corresponding wear rates at $500 \mathrm{r} / \mathrm{min}$ and $1800 \mathrm{r} / \mathrm{min}$ are shown in Figure 9, i.e., 2.25 $\mathrm{mg} / \mathrm{m}$ and $5.81 \mathrm{mg} / \mathrm{m}$, respectively.

As shown in Figure 10(a), the surface of the upper samples at $500 \mathrm{r} / \mathrm{min}$ does not show severe adhesive wear; however, there is severe adhesive wear on the surface under the condition of $1800 \mathrm{r} / \mathrm{min}$ (Figure 10(b)). After the test, a lot of $\mathrm{CuPb} 15 \mathrm{Sn} 5$ debris were found on the friction surface under the condition of $1800 \mathrm{r} / \mathrm{min}$. The reasons may be as follows: on the one hand, it is impossible to keep a complete oil film between the contact surfaces under the combined action of the centrifugal force and the contact pressure of $3 \mathrm{MPa}$; on the other hand, friction heat might soften the upper sample. In this test, both frictional heat and centrifugal force increase

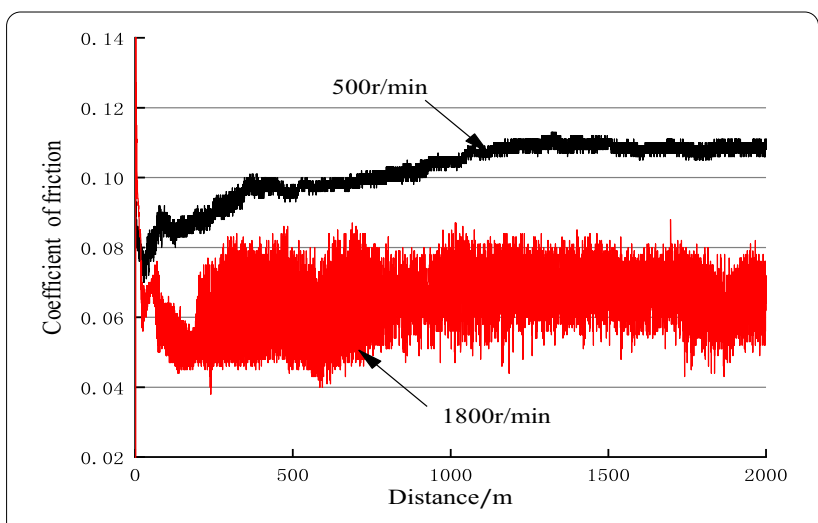

Figure 8 Friction coefficient under different speed

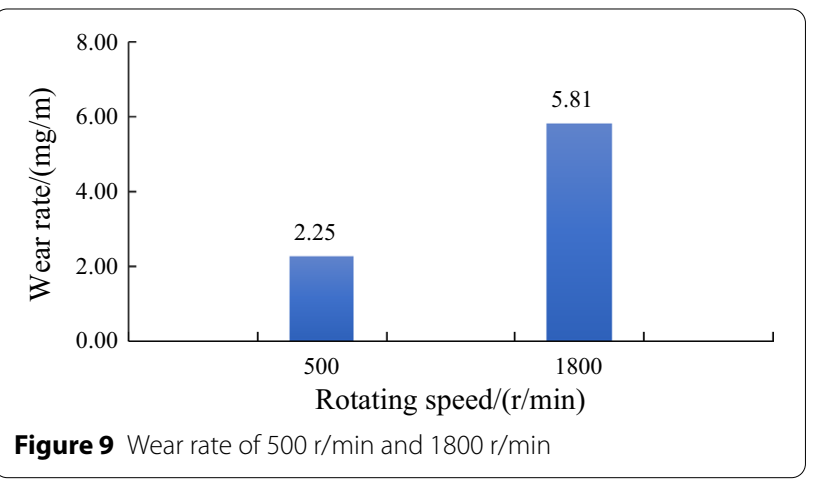

significantly with speed. Therefore, adhesive wear is aggravated as the rotational speed increases.

In addition, it can be inferred from Figure 10 that the fluctuation in the friction coefficient at $1800 \mathrm{r} / \mathrm{min}$ might result from three-body abrasive wear. The process is generally as follows: adhesion wear occurs because of high contact pressure and high rotational speed, then adhered copper material is knocked off and is crushed into a large amount of loose wear abrasives, these loose abrasive particles will slide across the wearing surface, just acting as rolling bearings between the friction surfaces, which will convert the sample from sliding friction to rolling friction, thereby reducing the friction coefficient. However, due to the differences in the shape and size of these loose abrasive copper particles, and they are not evenly distributed between the friction surfaces, which will make the friction pair rotate unevenly, and then the friction coefficient curve fluctuates.

\subsection{Effect of Contact Pressure on Tribological Characteristics}

In this section, the samples are from 'experiment 1' in Table 2. The operating speed was $1800 \mathrm{r} / \mathrm{min}$. During the test, the contact pressure was set as $1 \mathrm{MPa}, 1.5 \mathrm{MPa}, 2$ $\mathrm{MPa}, 2.5 \mathrm{MPa}$ and $3 \mathrm{MPa}$, respectively. As shown in Figure 11 , under the condition of $1 \mathrm{MPa}, 1.5 \mathrm{MPa}, 2 \mathrm{MPa}$ and $2.5 \mathrm{MPa}$, the friction pair goes through a short running-in wear stage in which the friction coefficient gradually decreases, then it reaches a stable wear stage, their average friction coefficients at stable stage are 0.075, 0.07, 0.065 and 0.08 , respectively.

Within the contact pressure range of $1-2 \mathrm{MPa}$, the friction coefficient decreases with the increase of contact pressure; as the contact pressure increases to 2.5 $\mathrm{MPa}$, the friction coefficient is about 0.08 . This trend matches the relation between friction and Sommerfield Number [25]. The Sommerfeld Number is a dimensionless quantity used extensively in hydrodynamic lubrication analysis. From a macroscopic point of view, when 


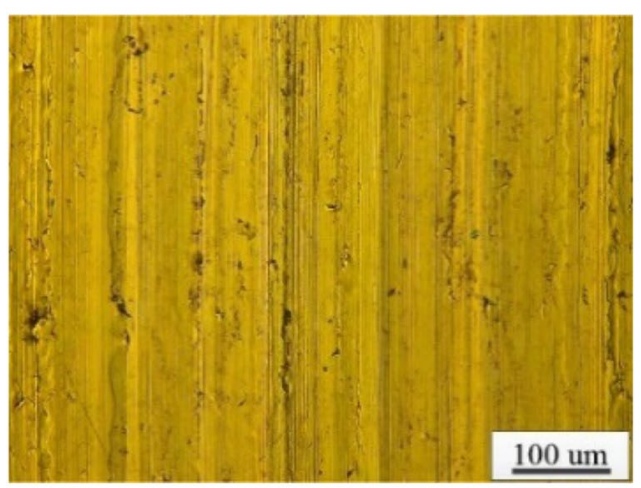

(a) $500 \mathrm{r} / \mathrm{min}$

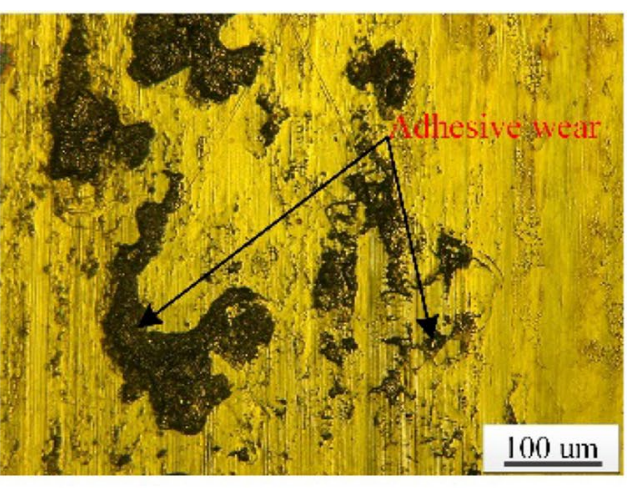

(b) $1800 \mathrm{r} / \mathrm{min}$

Figure 10 Surface morphology of the upper samples

the rotational speed and fluid viscosity are constant, the Sommerfield Number decreases as the contact pressure increases. Under full fluid film lubrication condition, the friction coefficient decreases as Sommerfield Number decreases. Once the conditions like the contact pressure decreasing the Sommerfield Number enough, the interface transitions to mixed lubrication or boundary lubrication. Under the condition of mixed lubrication or boundary lubrication, the contact of the surfaces begins to occur between the asperities, so the friction level increases sharply. In addition, it should pointed out that a large amount of debris were found in the oil box under the condition of $2.5 \mathrm{MPa}$ after the experiment, and the maximum temperature have reached $50{ }^{\circ} \mathrm{C}$ (as shown in Figure 12), which was higher than that under $2 \mathrm{MPa}$ condition as for 1-2 $\mathrm{MPa}$, there is little debris in the oil box after experiment.

When the contact pressure is further increased to $3 \mathrm{MPa}$, the experimental friction coefficient becomes extremely unstable. As can be seen from Figure 11(e), the friction coefficient fluctuates between 0.045 and 0.08 . The reason is that the loose abrasive particles generated by the adhesive wear are present on the friction surface, which act as rolling bearings between the surfaces to reduce the friction coefficient.

The wear rate at the contact pressure of $1 \mathrm{MPa}, 1.5$ $\mathrm{MPa}, 2 \mathrm{MPa}, 2.5 \mathrm{MPa}$ and $3 \mathrm{MPa}$ are shown in Figure 13. As shown, the wear rate increases nonlinearly as the contact pressure increases. It increases slowly when the contact pressure is less than $2.5 \mathrm{MPa}$; once the contact pressure exceeds $2.5 \mathrm{MPa}$, it is sharply increased.

Figures 14, 15 illustrate the surface morphology of the sample after tests. Since the rate of wear is low at the contact pressure of $1 \mathrm{MPa}$ and $1.5 \mathrm{MPa}$, the original processing marks on the surface of upper samples are still clearly visible, as shown in Figure 14(a), (b). At the contact pressure of $2 \mathrm{MPa}$, the original morphology of the upper sample disappears, and its surface is smoother than that before the experiment, as shown in Figure 14(c). There are no scratches or adhesive wear on the surface of the $t$ upper samples shown in Figure 14(a)-(c).

As described in Section 2.2, the surface roughness of the upper and lower samples are $0.2 \mu \mathrm{m}$ and $0.4 \mu \mathrm{m}$, respectively. In other words, there are some asperities on every surface. These asperities may be preserved under light load and full film lubrication conditions, such as $1 \mathrm{MPa}$ and $1.5 \mathrm{MPa}$. As the load is greater than the critical value, the tips of these asperities contact each other because of the breakdown of the lubricant film, and the "real" contact area is much smaller than the dimensions of friction pair, then the asperities are quickly loaded beyond their yield stress. As a result, the plastic deformation makes the surface of the friction pair look smoother. This phenomenon is consistent with the test results under $2 \mathrm{MPa}$ operating conditions (Figure 14(c), (f)).

As the load is further increased, the subsequent relative movement of the friction pair would make the joined asperities shear each other, and then new junctions form. If the force of adhesion at the junction between the two surfaces is higher than cohesion, the shearing might occur at the base of one of the asperities. As a result, the material from one surface may be transferred to the other one, which is known as adhesive wear. This description is consistent with the test results under $2.5 \mathrm{MPa}$ condition. As shown, a small amount of adhesive wear appears on the sample surface shown in Figure 15(a), and the surface of the lower sample is slight oxidized due to friction heat (Figure 15(c)). 


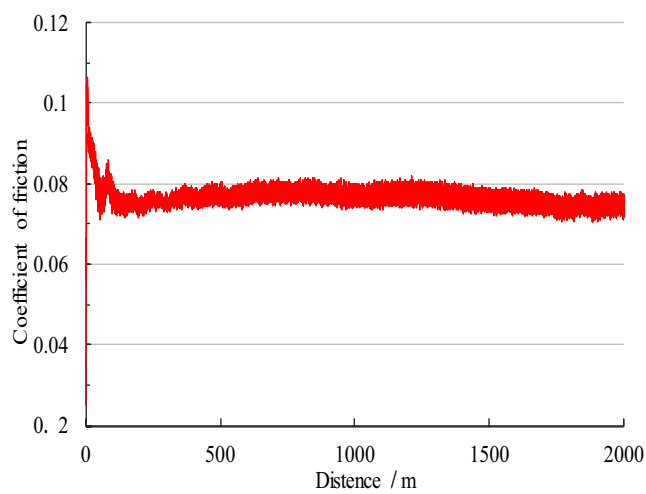

(a) $1 \mathrm{MPa}$

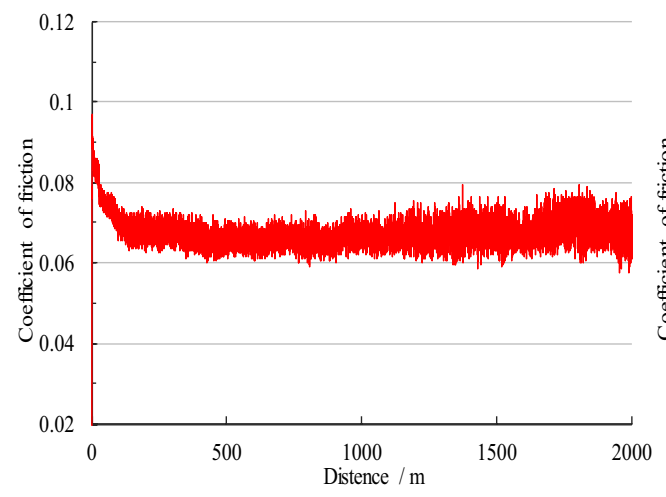

(c) $2 \mathrm{MPa}$

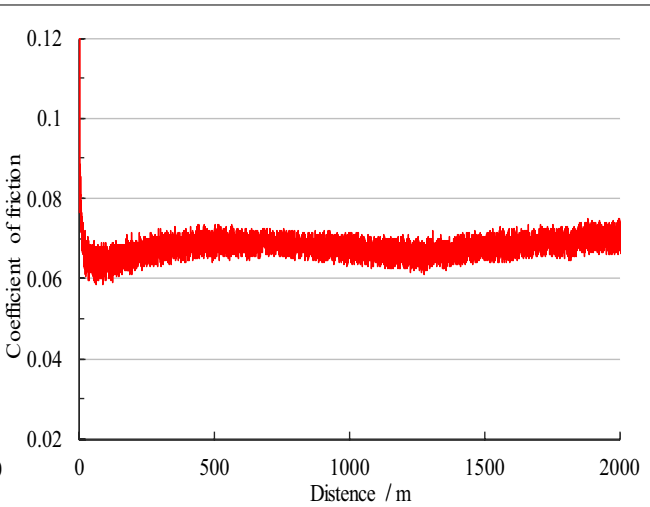

(b) $1.5 \mathrm{MPa}$

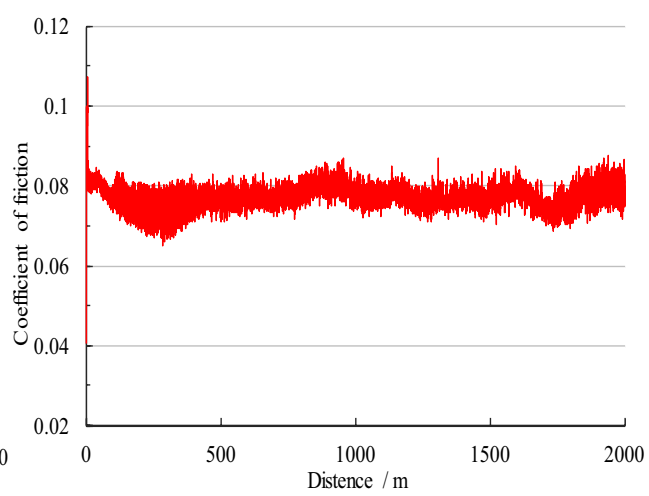

(d) $2.5 \mathrm{MPa}$

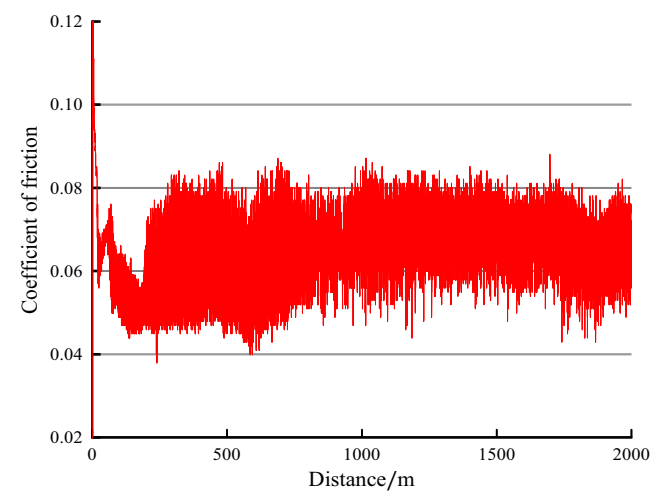

(e) $3 \mathrm{MPa}$

Figure 11 Friction coefficient at $1800 \mathrm{r} / \mathrm{min}$

As the contact pressure is increased to $3 \mathrm{MPa}$, severe wear occurs on the upper sample (Figure 15(b)), and several pieces of bronze are torn away from its surface. For the lower sample shown in Figure 15(d), some bronze particles adhere to its surface, and its surface is severely oxidized by the friction heating. The results indicate that the valve plate/cylinder block friction 


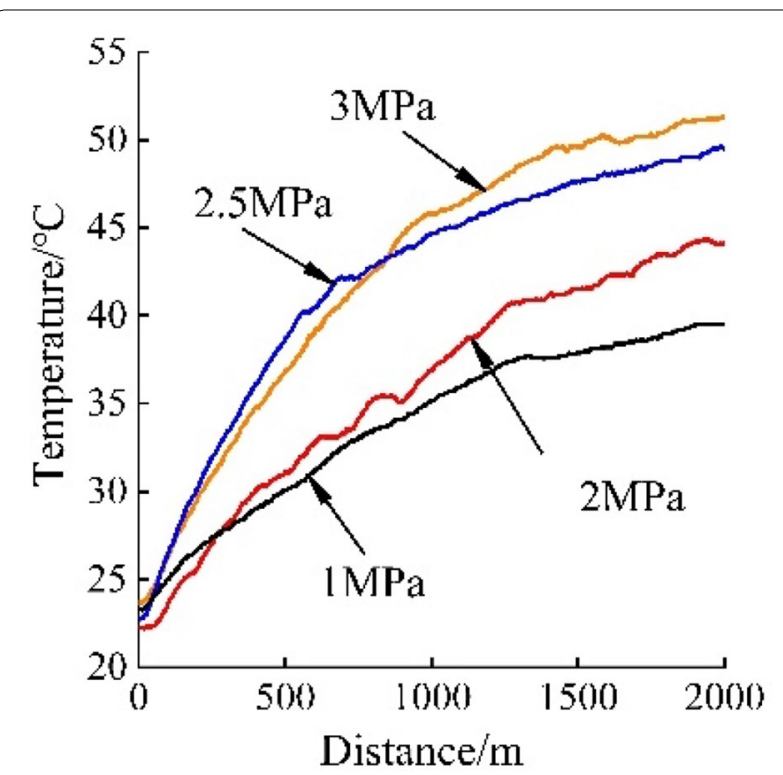

Figure 12 Effect of contact pressure on temperature at $1800 \mathrm{r} / \mathrm{min}$

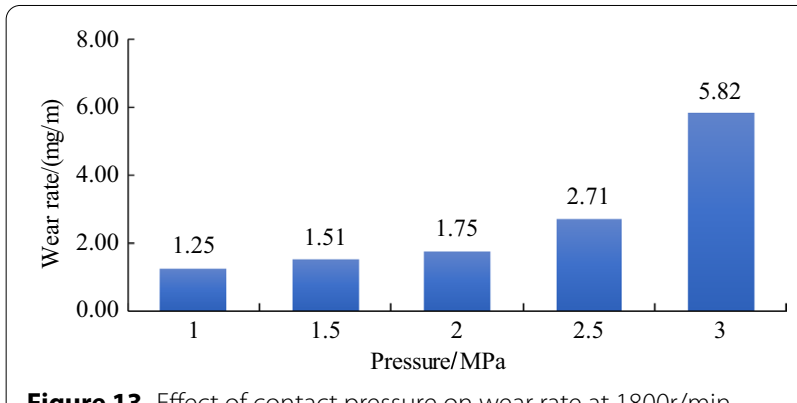

Figure 13 Effect of contact pressure on wear rate at 1800r/min

pairs cannot reach the specified life at the contact pressure of $3 \mathrm{MPa}$.

Obviously, it can be concluded from Figures 11(a)(c), 13 and 14 that the interface transitions to the mixed lubrication condition in the range of 1.5-2 MPa. The wear rate is sharply increased when the contact pressure is higher than $2.5 \mathrm{MPa}$. Based on the above results, 2.5 $\mathrm{MPa}$ and $1800 \mathrm{r} / \mathrm{min}$ are selected as subsequent experimental parameters.

\subsection{Effect of Material and Processing Treatment on the Tribological Performance \\ 3.3.1 Friction Coefficient and the Wear Rate}

In this section, the contact pressure is $2.5 \mathrm{MPa}$ and the operating speed is $1800 \mathrm{r} / \mathrm{min}$. Figure 16(a) shows the friction coefficients of $38 \mathrm{CrMoAl}$ samples with different treatment. As shown, the friction coefficient of the 'control group 1' gradually increases from 0.06 to 0.1 in the initial stage, then it rapidly increases to a certain value and starts to fluctuate, the average value is about 0.12 . The friction coefficients of the 'control group 2' and the 'experiment 1 ' are between 0.07 and 0.08 , it seems that the curve of 'experiment 1' is more stable than that of 'control group 2'.

Figure 16(b) shows the friction coefficients of $42 \mathrm{CrMo}$ samples with different heat treatment. The friction coefficient of the 'control group 3' slowly decreases from 0.08 to 0.07 . In the 'control group 4', it remains stable after a brief increase, but exceeds 0.11 and fluctuates greatly in the second half of the test. After the quenching and tempering processes, the 'experiment 2' shows a significant improvement compared with the 'control group 4', but there still exists fluctuations in the later stage.

Figure 17 illustrates the wear rate of upper sample in each experiment. It can be found that the wear rate is consistent with the friction coefficient. For $38 \mathrm{CrMoAl}$ with different treatment, the 'experiment 1 ' experiences the lowest wear rate, namely, $2.7 \mathrm{mg} / \mathrm{m}$; and those of 'control group 1' and 'control group 2' are $8.95 \mathrm{mg} / \mathrm{m}$ and $6.35 \mathrm{mg} / \mathrm{m}$, which are 3.3 times and 2.4 times as high as that of the 'experiment 1', respectively. As for the 42CrMo with different treatment, the 'control group 3' has the lowest wear rate, namely, $3.65 \mathrm{mg} / \mathrm{m}$; and those of 'control group 4' and 'experiment 2' are $8.15 \mathrm{mg} / \mathrm{m}$ and 4.4 $\mathrm{mg} / \mathrm{m}$.

Comprehensive comparison of the above tests, it can be found that the wear characteristics of $38 \mathrm{CrMoAl}$ and $42 \mathrm{CrMo}$ are quite different. The wear rate of $38 \mathrm{CrMoAl}$ without any heat treatment is $145 \%$ higher than that of $42 \mathrm{CrMo}$ under the same condition; the wear rate of $38 \mathrm{CrMoAl}$ treated by nitriding process is $22 \%$ lower than that of $42 \mathrm{CrMo}$; the wear rate of $38 \mathrm{CrMoAl}$ treated by tempering, quenching and nitriding process is $38 \%$ lower than that of $42 \mathrm{CrMo}$.

\subsubsection{Surface Topography}

Figure 18 shows surface topography of the friction pairs with $38 \mathrm{CrMoAl}$ lower sample. For 'control group 1 ', the upper sample is severely worn (Figure 18(a)), the marks of adhesive wear exceeds $198 \mu \mathrm{m}$ in diameter and scratches produced by abrasive also exceeds $70 \mu \mathrm{m}$; there also exists severe wear on the lower sample shown in Figure 18(d), it can be found that scratches with a width greater than $100 \mu \mathrm{m}$ appear on it, and bronze particles adhere to the surface.

Compared with the test results of the 'control group 1', the surface wear of the 'control group 2' is slight. As illustrated in Figure 18(b), both scratches and adhesive wears are found on the upper sample surface, and the plastic deformation occurs on its surface, too; Figure 18(e) is the lower sample paired with it, it can be found that its surface roughness has disappeared, some bronze particles 


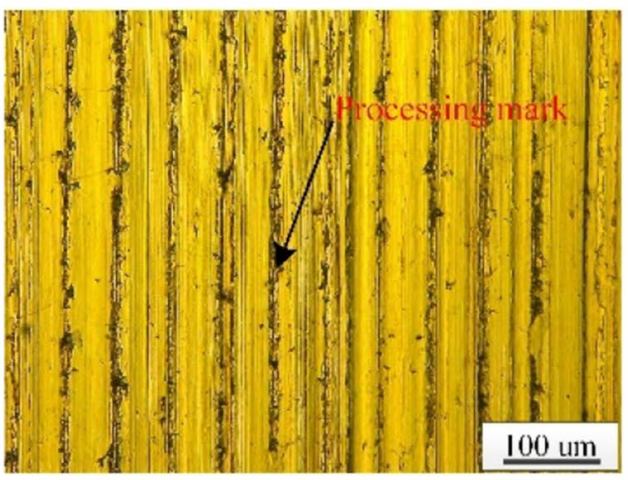

(a) Upper sample $1 \mathrm{MPa}$

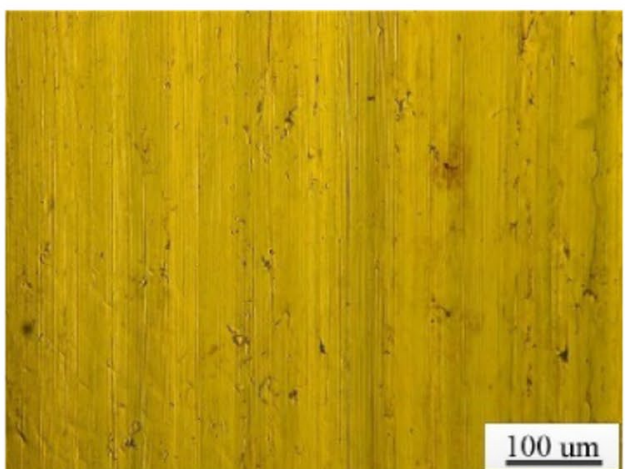

(c) Upper sample $2 \mathrm{MPa}$

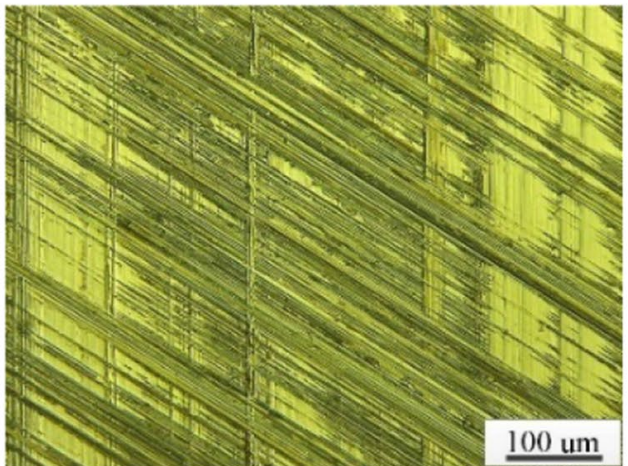

(e) Lower sample $1.5 \mathrm{MPa}$

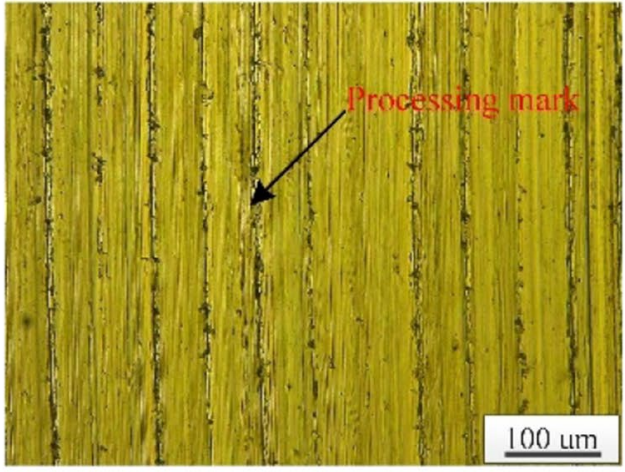

(b) Upper sample $1.5 \mathrm{MPa}$

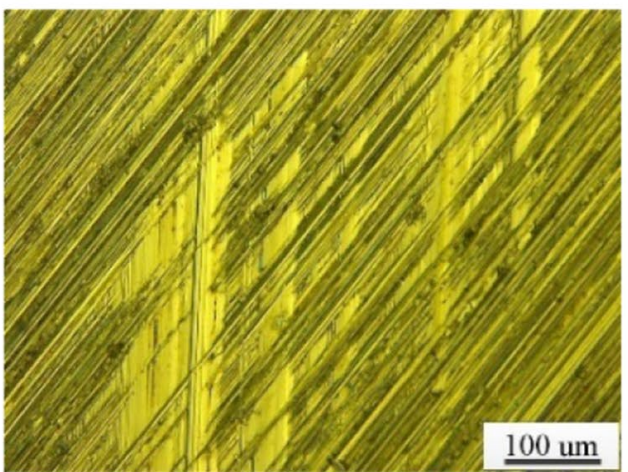

(d) Lower sample $1 \mathrm{MPa}$

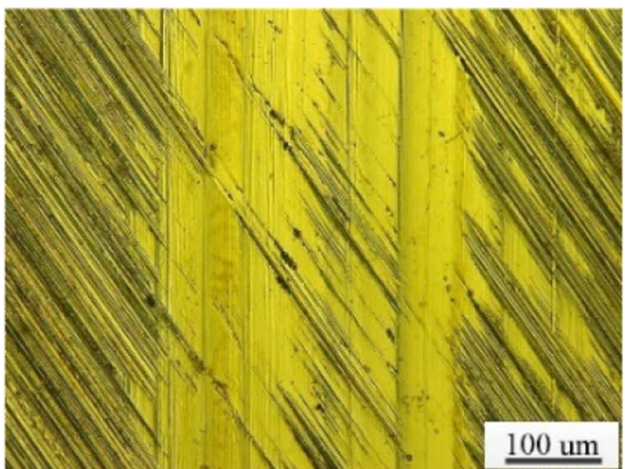

(f) Lower sample $2 \mathrm{MPa}$

Figure 14 Surface morphology of the samples at $1800 \mathrm{r} / \mathrm{min}$

accumulate and have been transferred to its surface. Bronze particles transferred to the lower sample would come into contact with the upper sample, and eventually form adhesive wear or indentation (plastic deformation) on the upper sample.
Figure 18(c), (f) depicts the surface topography from 'experiment 1', its wear seems to be the slightest. For the upper sample shown in Figure 18(c), some adhesive wear and scratches exist on its surface as well, but these are negligible by comparison with Figure 18(a), (b); the lower sample paired with it is shown in Figure 18(f), it can be 


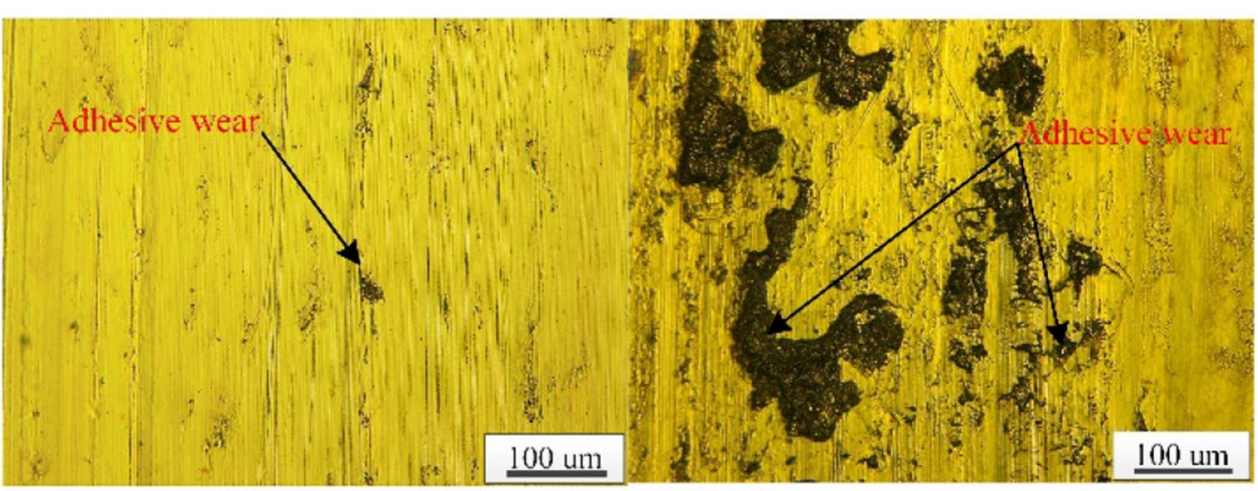

(a) Upper sample $2.5 \mathrm{MPa}$

(b) Upper sample $3 \mathrm{MPa}$

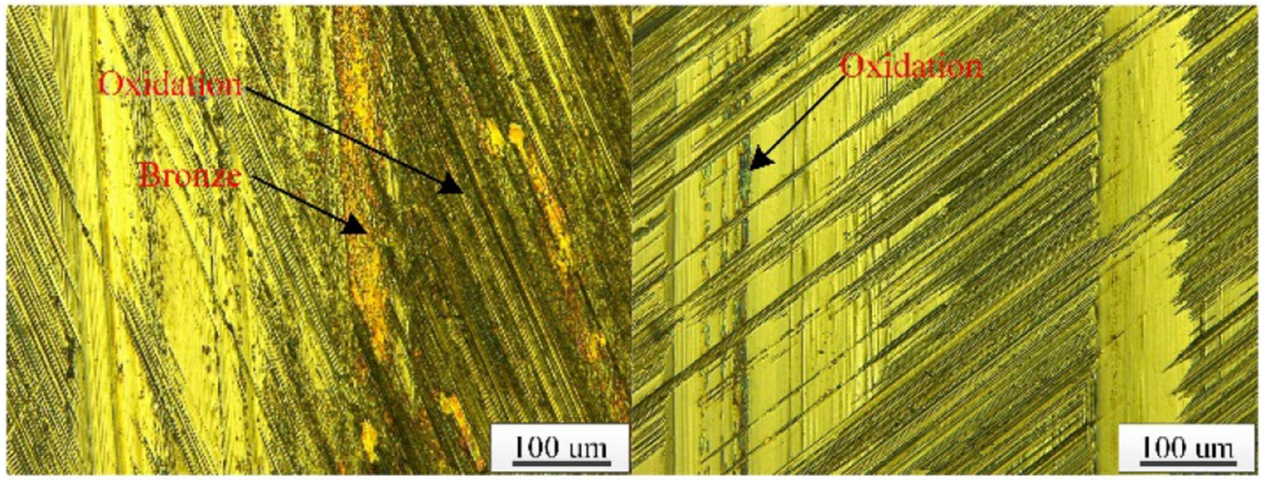

(c) Lower sample $2.5 \mathrm{MPa}$

(d) Lower sample $3 \mathrm{MPa}$

Figure 15 Surface morphology of samples under 2.5 and $3 \mathrm{MPa}$

found that its surface is smooth and bronze particles are transferred to its surface as well.

Figure 19 shows the surface topography of the friction pairs with $42 \mathrm{CrMo}$ lower sample. For 'control group 3 , there is a small amount of adhesive wear and slight indentations on its upper sample surface (Figure 19(a)); and some bronze particles are evenly spread between the lower-sample roughness peaks (Figure 19(d)), thereby smoothing its surface.

With respect to the 'control group 4', the upper sample seems to experience severe adhesive wear, and there are also serious scratches on it (Figure 19(b)). It can be found from Figure 19(e) that the roughness peaks on the lower sample have disappeared, and a large amount of bronze has accumulated on its surface; in addition, its entire friction area is covered with oxidized marks.

As depicted in Figure 19(c), adhesive wear and scratches also occur on the upper sample from the 'experimental 2', but the wear rate is slighter than that of the 'control group 4'. Apart from that, the lower sample also shows an improvement in wear resistance, as illustrated in Figure 19(f). It could be found that only a small amount of bronze adheres to its surface, and its surface scratches and oxidation phenomena are also significantly reduced.

\section{Wear Mechanisms}

The friction pair composed of $\mathrm{CuPb} 15 \mathrm{Sn} 5$ and $38 \mathrm{CrMoAl}$ or $42 \mathrm{CrMo}$ usually has a short running-in wear stage, then it reaches a stable wear stage. In the running-in wear stage, the friction coefficient gradually decreases and exhibits unstable behavior, and this period appears in all the tests in this paper. During the stable wear stage, the heat treatment of the $38 \mathrm{CrMoAl}$ or $42 \mathrm{CrMo}$ will have a greater impact on the friction and wear characteristics.

The lower sample made of $38 \mathrm{CrMoAl}$ without any heat treatment has the worst wear resistance. At the initial stage of the test, the bronze particles generated by the 


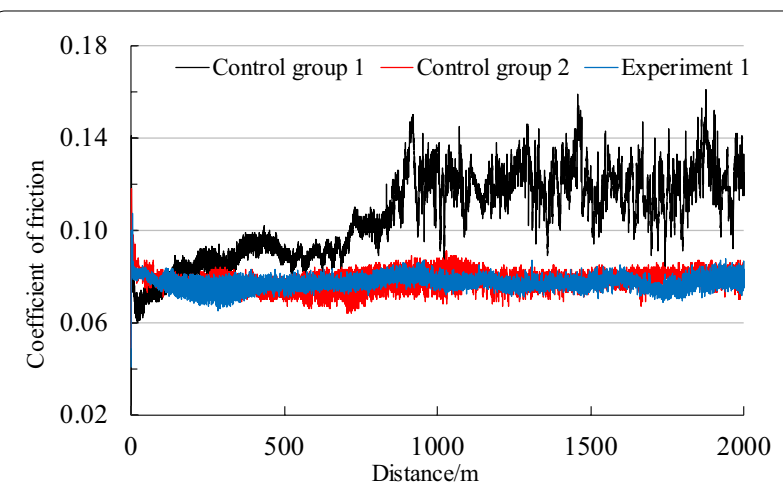

(a) $38 \mathrm{CrMoAl}$

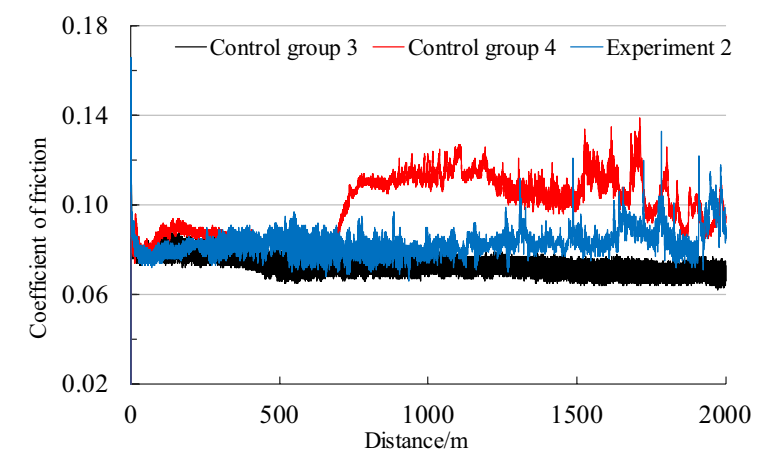

(b) $42 \mathrm{CrMo}$

Figure 16 Friction coefficient

abrasion will adhere to the surface of $38 \mathrm{CrMoAl}$ sample and gradually accumulate. As a result, the bronze-bronze contact occurs between the friction surfaces, which leads to adhesive wear. Adhesive wear further exacerbates the surface roughness of the bronze sample, which is more likely to produce scratches on the $38 \mathrm{CrMoAl}$ surface and aggravate the wear of the friction pair because the hardness difference between the upper and lower samples is not obvious. However, the tribological properties of the
42CrMo without any heat treatment are better than that of $38 \mathrm{CrMoAl}$ under the same test conditions. In this case, the bronze particles from the upper sample are evenly spread between the roughness peaks instead of accumulating on the lower sample. With respect to $42 \mathrm{CrMo}$ lower sample without any heat treatment, there will be no serious wear between the friction surfaces.

After nitriding, the metallographic structures of the lower samples made of $38 \mathrm{CrMoAl}$ or $42 \mathrm{CrMo}$ don't change. But the lower sample is greatly improved on the hardness and becomes more wear-resistant. As for the friction pairs of $\mathrm{CuPb} 15 \mathrm{Sn} 5 /$ nitrided $38 \mathrm{CrMoAl}$, bronze particles accumulated on the surface of nitrided $38 \mathrm{CrMoAl}$ make the bronze surface more susceptible to adhesive wear or plastic deformation. However, the rough surface of the bronze sample does not produce scratches on the surface of nitrided $38 \mathrm{CrMoAl}$ sample because of the extremely high hardness of the latter. As for the friction pairs of $\mathrm{CuPb} 15 \mathrm{Sn} 5 /$ nitrided $42 \mathrm{CrMo}$, the accumulation of bronze particles on the surface of nitrided $42 \mathrm{CrMo}$ is higher than that of nitrided $38 \mathrm{CrMoAl}$. Therefore, the adhesive wear of $\mathrm{CuPb} 15 \mathrm{Sn} 5 /$ nitrided 42CrMo friction pairs is worse than that of $\mathrm{CuPb} 15 \mathrm{Sn} 5 /$ nitrided $38 \mathrm{CrMoAl}$. The adhesion wear may lead to the increase in the friction coefficient and scratches, and even oxidation on the lower sample.

After quenching, tempering and nitriding, the surface microstructure of the lower sample is fined. Carbide is well-distributed and the surface characteristics are improved. Due to the improvement of the surface characteristics, only a small amount of the bronze particles generated by the abrasive wear adheres to its surface. The surface of quench-tempered and nitrided $38 \mathrm{CrMoAl}$ is hardly adhered by bronze particles, so there is only slight adhesive wear on the surface of the bronze sample. As for quench-tempered and nitrided $42 \mathrm{CrMo}$, there is a small amount of bronze particles on its surface, so there is also

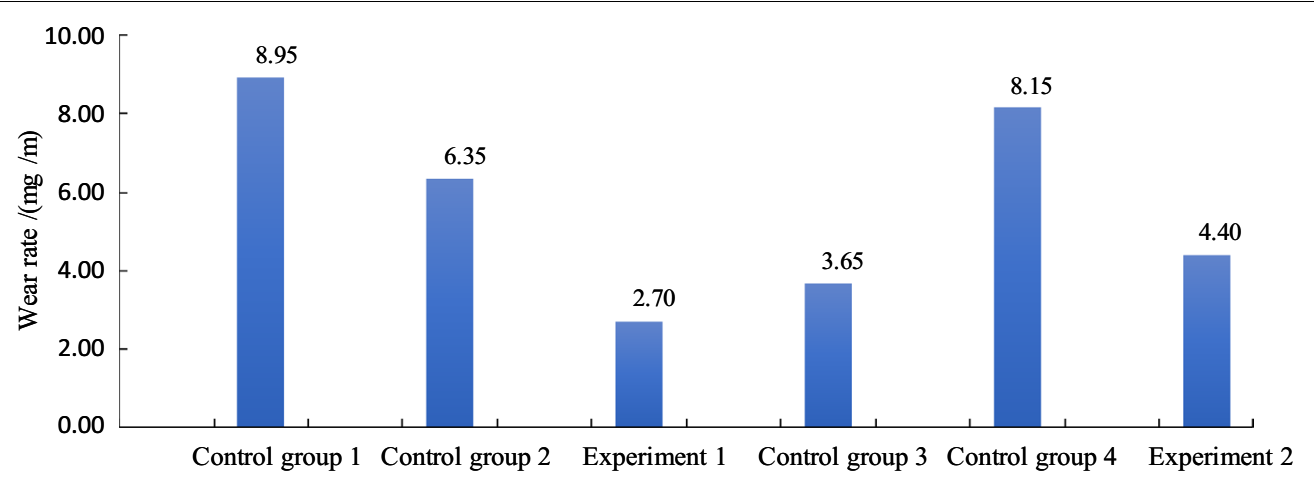

Figure 17 Comparison of experimental average wear rate 


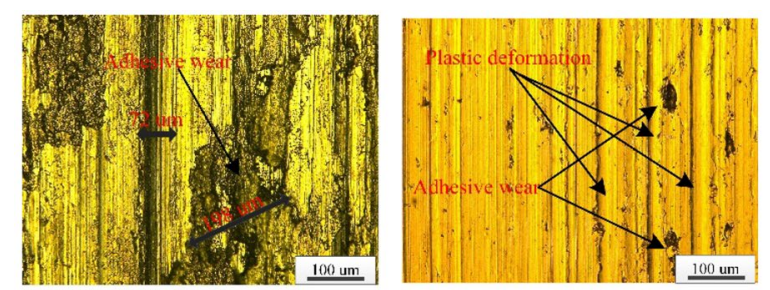

(a)Upper sample control group 1 (b) Upper sample control group 2

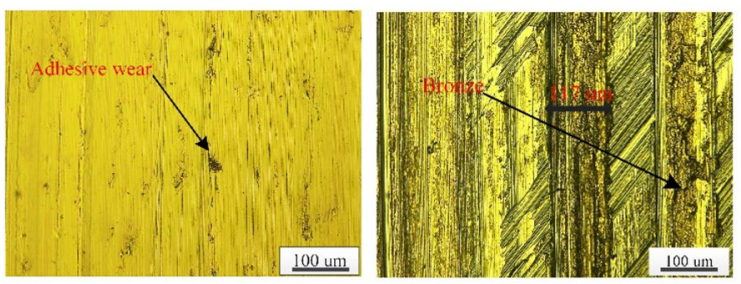

(c) Upper sample experiment 1 (d) Lower sample control group 1
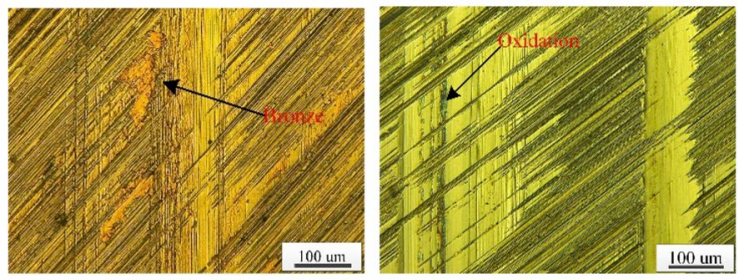

(e) Lower sample control group 2 (f) Lower sample experiment 1

Figure 18 Surface morphology of the samples with 38CrMoAl lower sample

adhesive wear and scratches on the surface of the bronze sample.

\section{Research Applications}

Steel (usually 38CrMoAl, 42CrMo) and copper (usually $\mathrm{CuPb} 15 \mathrm{Sn} 5$ ) materials have been used for the manufacture of valve plates and cylinder block for a long time. Although some researchers have tried to use new materials or cutting-edge coating technology to improve the wear resistance; in practice, most of the valve plate-cylinder block pairs still use iron-copper materials because of cost issues. Therefore, it is of great significance to fully exploit the potential performance of some common metal materials to meet the design requirements of axial piston pumps through heat treatment and friction material selection. For example, the results in this paper have confirmed that $\mathrm{CuPb} 15 \mathrm{Sn} 5 /$ quench-tempered and nitrided $38 \mathrm{CrMoAl}$ is more suitable for valve plate/cylinder block than CuPb15Sn5/quench-tempered and nitrided 42CrMo.

Figure 20 illustrates the friction and wear characteristics of the valve plate and cylinder block inside a real axial piston pump, which had been operated for a period of time under the conditions of $30 \mathrm{MPa}$ delivery pressure
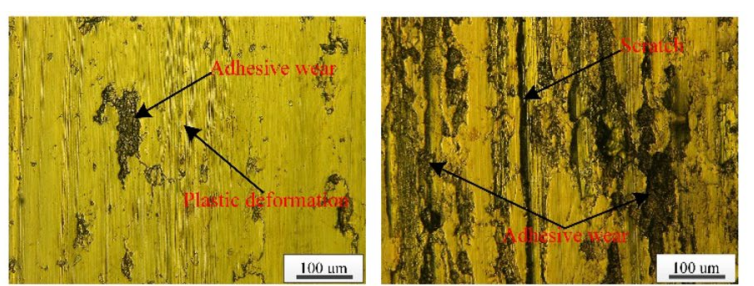

(a)Upper sample control group 3 (b) Upper sample control group 4
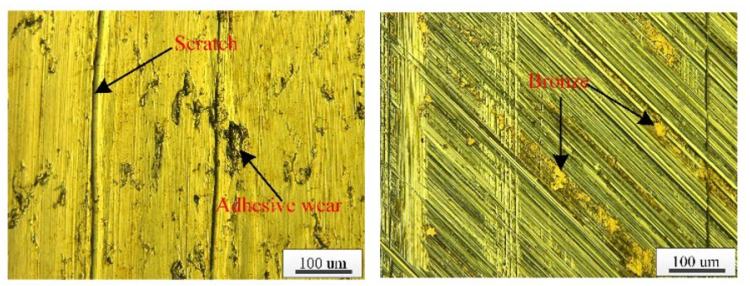

(c) Upper sample experiment 2 (d) Lower sample control group 3
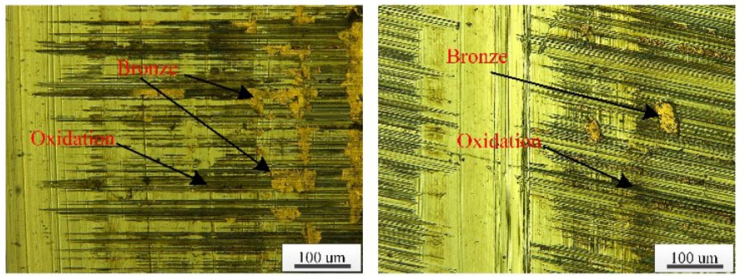

(e) Lower sample control group 4 (f) Lower sample experiment 2

Figure 19 Surface morphology of the test samples with $42 \mathrm{CrMo}$ lower sample

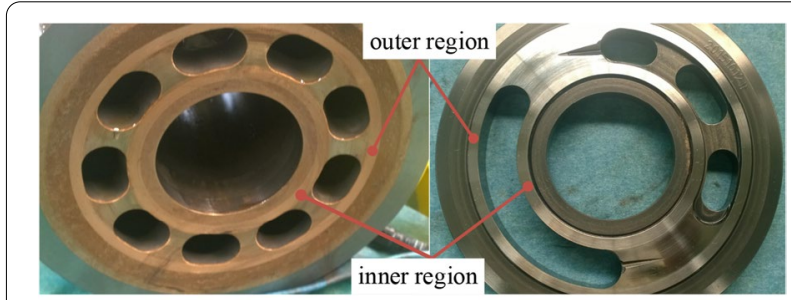

(a) Cylinder block

(b) Valve plate

Figure 20 Friction and wear characteristics of valve plate/cylinder block in a real piston pump

and $1450 \mathrm{r} / \mathrm{min}$. Observed with naked eyes, there are some visible signs of friction on their surfaces; however, there is no serious adhesive wear and abrasive wear because of fluid films.

Figure 21 shows the contour curves of the valve plate and cylinder block, which were measured by WENZEL ${ }^{\circledR}$ Coordinate Measuring Machine (Model: LH87), the curve labelled "original contour" refers to the contour curve of a new valve plate or cylinder block along the radius; and the curves labelled "contour 1", "contour 2", 


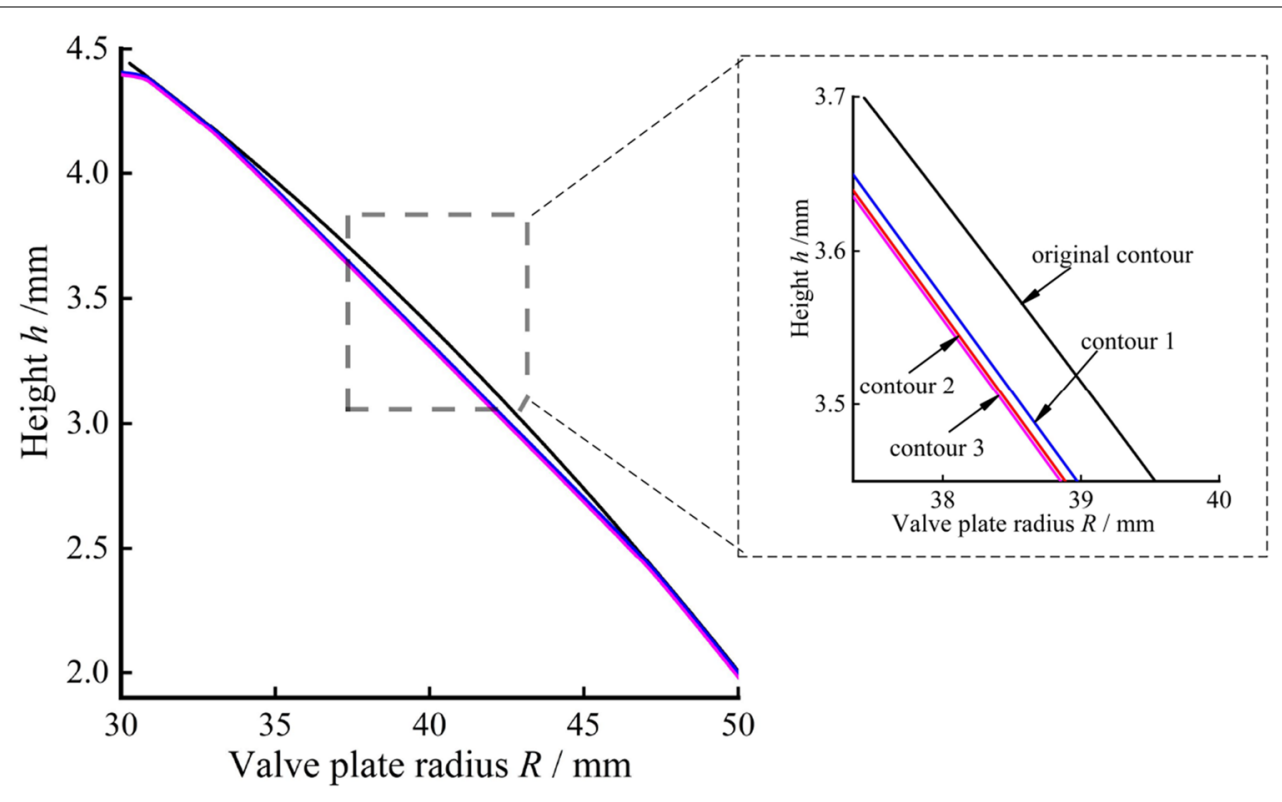

(a) Contour curves of valve plate

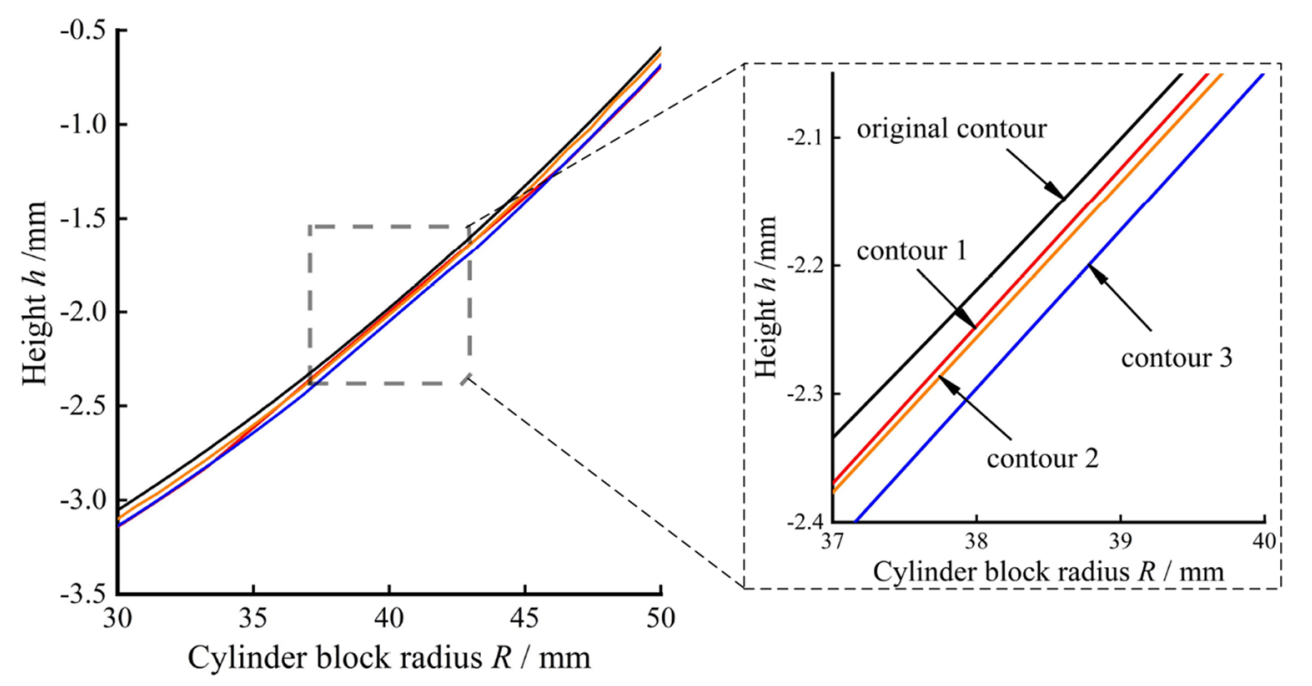

(b) Contour curves of cylinder block

Figure 21 Contour of valve plate/cylinder block

"contour 2" are the test profiles of the worn valve plate or cylinder block, which are 120 degrees apart in the circumferential direction. It can be concluded that the friction and wear is relatively slight.

As illustrated in Figure 1, cylinder block is pressed against the valve plate to create a sealing surface by combination of spring force, $F_{k}$, and the force generated by high - pressure oil. So Eq. (6) is rewritten, the contact pressure at the interface between the valve plate and cylinder block is,

$$
p_{\text {Load }}=\frac{\sum_{i=1}^{n} A_{b} \cdot p_{i}+F_{k}-A \cdot p_{s}}{A}=\frac{A_{b}}{A} \sum_{i=1}^{n} p_{i}-p_{s}+\frac{F_{k}}{A},
$$

In order to avoid the adhesive wear of the axial piston pump under a certain speed condition, it should be 


$$
\left[p_{n}\right]<p_{\text {Load }}=\frac{A_{b}}{A} \sum_{i=1}^{n} p_{i}-p_{s}+\frac{F_{k}}{A}
$$

where $\left[P_{n}\right]$ is the ultimate contact pressure of the friction pair metal material under a certain speed condition.

It can be known from Eq. (8) that it is related to the axial piston pump mechanical structure and delivery oil pressure. However, as far as I know, the design of $A_{b}$ does not take into account the factors of the contact pressure. For example, $A_{b}$ is calculated by Ref. [26].

$$
B_{b}=\frac{A_{p}-A_{b}}{A_{p}} \times 100 \%,
$$

where $B_{b}$ is the cylinder-block balance coefficient, typical values for $B_{b}$ range between $90 \%$ and $100 \% ; A_{p}$ is the cross-sectional area of each piston.

As found in previous experiments, $\left[P_{n}\right]$ of the valve plate/cylinder block is $2.5 \mathrm{MPa}$, so Eq. (8) can be regarded as a constraint in the optimization of the valve plate/ cylinder block,and then a more reasonable mechanical structural parameter may be obtained, thereby improving the working performance of the axial piston pump.

\section{Conclusions}

Test results indicates that adhesive wear and abrasive wear are the two wear models likely to be present at the valve plate/cylinder block in an axial piston hydraulic pumps. The wear is closely related to speed, contact pressure and heat treatment.

(1) The samples are more prone to adhesive wear at a speed of $1800 \mathrm{r} / \mathrm{min}$ than $500 \mathrm{r} / \mathrm{min}$, which implies that the tribological properties of the valve plate/ cylinder block samples should be evaluated around the normal operating speed of axial piston pump, so that the results would be more valuable for industrial application.

(2) Both material and heat treatment play a key impact on the tribological properties of the samples. The wear rate of $\mathrm{CuPb} 15 \mathrm{Sn} 5 / 38 \mathrm{CrMoAl}$ without heat treatment is $145 \%$ higher than that of $\mathrm{CuPb} 15 \mathrm{Sn} 5 / 42 \mathrm{CrMo}$ without heat treatment. The friction pair, CuPb15Sn5/quench-tempered and nitrided $38 \mathrm{CrMoAl}$, exhibits excellent tribological properties in all the test friction pairs, whose wear rate is $38 \%$ lower than that of CuPb15Sn5/ quench-tempered and nitrided 42CrMo. Therefore, $\mathrm{CuPb} 15 \mathrm{Sn} 5 /$ quench-tempered and nitrided $38 \mathrm{CrMoAl}$ is more suitable for the manufacture of valve plate/cylinder block than CuPb15Sn5/ quench-tempered and nitrided 42CrMo.
(3) For the samples made of $\mathrm{CuPb} 15 \mathrm{Sn} 5 /$ quenchtempered and nitrided $38 \mathrm{CrMoAl}$, the relationship between the contact pressure and the wear rate is non-linear at the speed of $1800 \mathrm{r} / \mathrm{min}$. The wear rate is sharply increased when the contact pressure is higher than $2.5 \mathrm{MPa}$. So the contact pressure of the valve plate/cylinder block should be less than $2.5 \mathrm{MPa}$, which will contribute to optimization design of the pressure bearing area at the bottom of the cylinder block.

(4) In the follow-up research, CuPb15Sn5/quenchtempered and nitrided 38CrMoAl, CuPb15Sn5/ quench-tempered and nitrided $42 \mathrm{CrMo}$ will be applied to the production of cylinder block/valve plate for real axial piston pumps; and comparative tests are carried out on the pumps assembled with these components to correct the process parameters and structural design parameters; these will be beneficial to the development and improvement of axial piston pumps.

\section{Acknowledgements}

The authors sincerely thanks to Professor Zhiqi Liu of Taiyuan University of Science and Technology, Xiaofeng Qin of Taiyuan University of Technology for their critical discussion and advice during test.

\section{Authors' Information}

Jiahai Huang, born in 1979, is currently a professor at College of Mechanical and Vehicle Engineering, Taiyuan University of Technology, China. He received his PhD degree from Zhejiang University, China, in 2011. His research interests include mechanical system dynamics, friction and lubrication, fluid power transmission.

Zhenhua Dou, born in 1995, is currently a master candidate at College of Mechanical and Vehicle Engineering, Taiyuan University of Technology, China. His research interest includes friction and wear.

Zhenglei Wang, born in 1994, is currently an engineer at China Railway Taiyuan Bureau Group Co., Ltd, China. He received his master degree from Taiyuan University of Technology, China, in 2019.

Long Quan, born in 1959, is currently a professor at College of Mechanical and Vehicle Engineering, Taiyuan University of Technology, China. His research interests include Mechatronic Engineering, fluid power transmission.

Linkai Niu, born in 1985, is currently a Lecturer at College of Mechanical and Vehicle Engineering, Taiyuan University of Technology, China. He received his PhD degree from Xi'an Jiaotong University, China, in 2016. His research interests include dynamic modeling and vibration.

\section{Authors' Contributions}

$J H$ and LQ were in charge of the whole trial; ZW and ZD wrote the manuscript; $Z W$ and $L N$ assisted with sampling and laboratory analyses. All authors read and approved the final manuscript.

\section{Funding}

Supported by National Natural Science Foundation of China (Grant Nos. 51775362, 51705351), International Cooperation Project of Shanxi Province (Grant No. 2016-002), Natural Science Foundation of Shanxi Province (Grant No. 201901D111054).

\section{Competing Interests}

The authors declare no competing financial interests. 
Received: 15 February 2020 Revised: 4 September 2021 Accepted: 11 November 2021

Published online: 04 December 2021

\section{References}

[1] M Vukovic, H Murrrnhoff. The next generation of fluid power systems. Procedia Engineering, 2015, 106: 2-7.

[2] W He, J H Huang, $\mathrm{H}$ M Hao, et al. Design and analysis of a swashplate control system for an asymmetric axial piston pump. Journal of Dynamic Systems, Measurement, and Control, Transaction of the ASME, 2020, 142(2): 021005.

[3] M Hu. Study on power losses and design technology for the surface topography of friction pairs of axial piston pump. Hangzhou: Zhejiang University, 2017.

[4] J H Huang, Z Yan, L Quan, et al. Characteristics of delivery pressure in the axial piston pump with combination of variable displacement and variable speed. Pro. IMechE Part I: Journal of Systems and Control Engineering, 2015, 229(7): 599-613.

[5] Z L Wang, Y C Wu, J H Huang. A study on the high-speed tribological performance of port plates in axial piston pumps. Chinese Hydraulics \& Pneumatics, 2019(8): 27-32. (in Chinese)

[6] A T Schenk. Predicting lubrication performance between the slipper and swashplate in axial piston hydraulic machines. West Lafayette: Purdue University, 2014.

[7] J H Zhang, Y Chen, B Xu, et al. Effect of surface texture on wear reduction of the tilting cylinder and the valve plate for a high-speed electro-hydrostatic actuator pump. Wear, 2018, 414-415: 68-78.

[8] C R Zhao, J H Jiang. Tribological properties of the material for valve plate in aviation kerosene axial piston pump. China institute of mechanical engineering fluid transmission and control branch: The 9th national conference on fluid power transmission and control (9th FPTC-2016) collection, Zhejiang, China, August 29-30, 2016: 5.

[9] Y Zhu, X Chen, J Zou, et al. A study on the influence of surface topography on the low-speed tribological performance of port plates in axial piston pumps. Wear, 2015, 338-339: 406-417.

[10] Y S Hong, S Y Lee, C B Kim, et al. Improvement of the low-speed friction characteristics of a hydraulic piston pump by PVD-coating of TiN. Journal of Mechanical Science and Technology, 2006, 20(3): 358-365.

[11] S Y Lee, S D Kim, Y S Hong, et al. Application of the duplex TiN coatings to improve the tribological properties of electro hydrostatic actuator pump parts. Surface and Coatings Technology, 2005, 193(1): 266-271.

[12] S Y Lee, Y S Hong. Effect of CrSiN thin film coating on the improvement of the low-speed torque efficiency of a hydraulic piston pump. Surface and Coatings Technology, 2007, 202(4): 1129-1134.
[13] Y S Hong, S Y Lee. A comparative study of $\mathrm{Cr}-\mathrm{X}-\mathrm{N}$ ( $\mathrm{X}=\mathrm{Zr}$, Si) coatings for the improvement of the low-speed torque efficiency of a hydraulic piston pump. Metals and Materials International, 2008, 14(1): 33-40.

[14] Y Chen, L Song, C K Zhang, et al. Plasma nitriding without formation of compound layer for 38CrMoAl hydraulic plunger. Vacuum, 2017, 143: 98-101.

[15] G Schuhler, A Jourani, S Bouvier, et al. Efficacy of coatings and thermochemical treatments to improve wear resistance of axial piston pumps. Tribology International, 2018, 126: 376-385.

[16] Y Li, H S Deng, X L Wang. Experiment on friction and wear performance of textured port plate pair. Journal of Aerospace Power, 2014, 29(7): 1591-1597.

[17] S Zhao, X L Wang. The effects of surface texture on the wear properties of mechanical seals made of metal and polymers. Tribology, 2015, 35(6): 761-767.

[18] H S Deng, HW Yu, S Qi, et al. Effect of uniformly distributed micro-pits on leakage of port plate pair. Journal of Southeast University (Natural Science Edition), 2012, 42(1): 72-76. (in Chinese)

[19] HW Yu, H S Deng, W Huang, et al. Effect of micro-dimple arrangement on tribological of sliding surface. Journal of China University of Mining and Technology, 2011, 40(6): 943-948.

[20] H S Deng, HW Yu, X L Wang. Study on tribological performance of textured port plates of axial piston pumps. Journal of Huazhong University of Science and Technology (Natural Science Edition), 2012, 40(6): 16-19.

[21] S F Wu, D R Gao, Y N Liang, et al. Experimental study on influence of dimples on lubrication performance of glass fiber-epoxy resin composite under natural seawater lubrication. Chinese Journal of Mechanical Engineering, 2017, 30(1): 110-117.

[22] S F Wu, D R Gao, Y N Liang, et al. Influence of non-smooth surface on tribological properties of glass fiber-epoxy resin composite sliding against stainless steel under natural seawater lubrication. Chinese Journal of Mechanical Engineering, 2015, 28(6): 1171-1176.

[23] J R BARBER. The influence of thermal expansion on the friction and wear process. Wear, 1967, 10(2): 155-159.

[24] A P Hekimoğlu, T Savaşkan. Effects of Contact Pressure and Sliding Speed on the Unlubricated Friction and Wear Properties of $\mathrm{Zn}-15 \mathrm{Al}-3 \mathrm{Cu}-1 \mathrm{Si}$ Alloy. Tribology Transactions, 2016, 59(6): 1114-1121.

[25] D Mishra, F J Sonia, D Srivastava, et al. Wear damage and effects of graphene-based lubricants/coatings during linear reciprocating sliding wear at high contact pressure. Wear, 2018, 400-401: 144-155.

[26] N Manring. Fluid power pumps \& motors: analysis, design, and control. New York: Mc Graw Hill Education, 2012.

\section{Submit your manuscript to a SpringerOpen ${ }^{\circ}$ journal and benefit from:}

- Convenient online submission

- Rigorous peer review

- Open access: articles freely available online

- High visibility within the field

Retaining the copyright to your article

Submit your next manuscript at springeropen.com 